\title{
Investigation of Physico-Chemical
}

\section{Characteristics of Stainless Steel Surface and Their Effect on the Appearance Aspects of the Alloy Surface}

\author{
Shilpa Vaidya, N. C. Debnath* \\ Physics Department, Institute of Chemical Technology, Matunga, Mumbai, India \\ Email: ^ndebnath5@rediffmail.com
}

How to cite this paper: Vaidya, S. and Debnath, N.C. (2019) Investigation of Physico-Chemical Characteristics of Stainless Steel Surface and Their Effect on the Appearance Aspects of the Alloy Surface. Journal of Surface Engineered Materials and Advanced Technology, 9, 55-87. https://doi.org/10.4236/jsemat.2019.94006

Received: May 24, 2019

Accepted: October 19, 2019

Published: October 22, 2019

Copyright $\odot 2019$ by author(s) and Scientific Research Publishing Inc. This work is licensed under the Creative Commons Attribution International License (CC BY 4.0).

http://creativecommons.org/licenses/by/4.0/

\begin{abstract}
Stainless steel alloy SS-304 is widely used in many engineering applications primarily for its excellent corrosion resistance, ease of fabrication and aesthetic appeal. Many kitchen appliances are made from SS-304 alloy because of its durability, ease of cleaning and beautiful finish. However, over the years of continuous usage and cleaning by detergent bar and abrasive clothes the initial brightness and shine of the plates and dishes undergo considerable degradation. In this work, we report the results of a thorough investigation of the physico-chemical characteristics of the surface regions of both new and old SS-304 plates of known history of continuous usage to identify the key physical and chemical factors that are responsible for the loss of shine. Several analytical techniques viz. SEM/EDX, AFM, XPS, XRD, Reflectance FTIR, Profilometry and Reflectance spectrometry in the visible region have been used for experimental investigation of surface structure, morphology, roughness profile, chemical composition and appearance measurements of several steel samples. In addition, glossmeter has been used to measure the gloss of the samples at certain specific angles. It seems that surface roughness is one of the key physical parameters that play an important role in the reduction of brightness and shine. The other parameter is the presence of a thin surface film on the steel surface. In order to analyze the experimental data and to predict the shine and brightness phenomena quantitatively, we have used Fresnel's theory to compute first the reflectance from each component of SS-304 alloy assuming it to be a smooth surface and then extended it to compute the reflectance of the alloy surface (SS-304). In order to interpret the reflectance from old and used plates, we have further used Beckmann's theory of light scattering from random rough surface to analyze and predict the appearance aspects of the alloy surface quantitatively. Both the experimental
\end{abstract}


and computed results show good agreement, thus validating the reflectance model used for computing the reflectance from SS-304 alloy surface and the appropriateness of Beckmann's model of random rough surface.

\section{Keywords}

Loss of Shine in SS-304 Alloy Surface, Surface Roughness, Appearance Measurements, SEM/EDX, AFM, XPS, XRD, Reflectance FTIR, Profilometry, Reflectance Spectroscopy, Gloss, Presence of Thin Surface Film, Beckmann's Model of Random Rough Surface

\section{Introduction}

Stainless steel is one of the most important and widely used engineering materials primarily for its excellent corrosion resistance and beautiful aesthetic appeal. In addition to its various engineering applications, stainless steel has gained popularity as a material for kitchen appliances and utensils due to economic reasons, aesthetic appeal, excellence in corrosion resistance, and durability. There are many additional advantages to the use of stainless steel like ease of maintenance and cleaning, ease of fabrication, impact resistance and its recycling value. Thus, the surface studies of stainless steel alloys are extremely important in the quantitative understanding of the appearance aspects of this alloy [1]-[10]. Stainless steel exists in three crystalline phases, viz. Austenite, Ferrite and Martensite [11] [12] [13], Austenitic being the most popular grade, especially for manufacturing the kitchenware. Austenitic steels are non-magnetic, have Face-centred-cubic (FCC) crystal structure and they possess excellent ductility, formability and toughness. SS-304 is the most commonly used Austenitic stainless steel grade in the manufacture of kitchenware. The major components of SS-304 are $\mathrm{Fe}, \mathrm{Cr}, \mathrm{Ni}$ and $\mathrm{Mn}$. The characteristic "stainless" and "corrosion resistant" properties of stainless steel can be attributed to the presence of $\mathrm{Cr}$ in the alloy.

Stainless steel surface can be given a highly reflecting mirror-like finish by polishing with successively finer abrasives and buffing extensively [6]. In addition, stainless steel is both hygienic as well as easy to clean and maintain. When in use as appliances or utensils in the kitchen, the alloy surfaces are exposed to various stresses, for example, thermal, chemical and mechanical, during handling and usage. Especially in the Indian kitchen, the use of ingredients like various oils, turmeric, milk etc., results in the strong adhesion of the soil to the utensils on exposure to high temperatures. In order to clean the soiled surface, a cleaning process is undertaken, which imparts a lot of mechanical stress to the substrate in the form of scrubbing action, abrasive powders, cleaning accessories etc., which contribute to further damage to the surface of the alloy. Consequently, a deterioration of the initial gloss or shine occurs over a period of time.

The current work aims at developing a scientific understanding of the appearance phenomenon of stainless steel alloy surface; to identify the important 
physical and chemical factors that are responsible for the initial shine or gloss of the alloy surface, and the mechanism of degradation of shine with time and usage. For this investigation we have used both experimental techniques and theoretical modeling of reflectance from smooth and rough surfaces to understand the appearance aspects of different samples. The important characterization techniques which are sensitive to the surface region viz. SEM/EDX, AFM, Reflection FTIR, XPS, Reflectance spectrophotometry in visible region, have been used in the present work. In addition we have also used XRD for phase analysis of stainless steel samples and profilometer and glossmeter for the measurement of surface roughness and gloss values at different angles, respectively.

\section{Experimental}

The samples used in the current work involve commercial grade SS-304 panels and dishes with different pretreatments and background. Polished, unpolished, chemically cleaned and oil-film deposited ones, along with 15 year-old SS plates have been used. The samples with appropriate labels for identification are classified as defined in Table 1.

All the panels could not be used for all the measurements because of the restrictions of sample size and geometry.

The experimental work begins with the cleaning of the sample surface to get rid of the residual contaminations. All the samples were cleaned in alkaline degreasing solution and the macroscopic cleanliness of the surface was tested by water-film-break test [ASTM F22-65] [7]. The procedure for sample cleaning is described below in (A).

\section{1) Preparation of clean metal surface:}

The S.S. panels were cleaned by dipping in a $15 \%(\mathrm{v} / \mathrm{v})$ solution of a liquid detergent for 1.5 hours at room temperature. The samples were then washed with a spray of line-water to free the surface from detergent, followed by a thorough rinse with deionised water. The samples were assessed for their cleanliness using the "Water-film-break test".

Wherever necessary, the samples were dipped for an additional period of 0.5 hour in a second bath of fresh cleaning solution.

Table 1. Classification of samples used.

\begin{tabular}{|c|c|c|}
\hline Sample no. & Code used & Sample with Pre-treatment \\
\hline 1 & SSPN & SS-304 Panel New_Chemically cleaned \\
\hline 2 & SSDN & SS-304 Dish New-Chemically cleaned \\
\hline 3 & SSOP & $\begin{array}{l}\text { SS-304 Old Plate-Chemically cleaned } \\
\text { (Known history-15 years of regular usage) }\end{array}$ \\
\hline 4 & SSPO & SS-304 New Panel with a Thin Oil-film adsorbed on the surface \\
\hline 5 & SSDO & SS-304 New Dish with a Thin Oil-film adsorbed on the surface \\
\hline 6 & $\mathrm{CPP}$ & SS-304 Commercial Panel Polished from panel manufacturer \\
\hline 7 & CPU & SS-304 Commercial Panel Unpolished from panel manufacturer \\
\hline
\end{tabular}


Samples of smaller dimensions $(1 \mathrm{~cm} \times 1 \mathrm{~cm})$ were placed in a stainless steel strainer which was dipped in the cleaning bath.

The samples were dried at room temperature and then used for further study.

All the samples were cleaned by the process described above, before being subjected to any further treatment or analysis.

In order to study the effect of an adsorbed oil film on the appearance characteristics of metal surface, a set of control panels was prepared where a thin oil film was deposited on the metal surface by solution technique [8] as described below in (2).

\section{2) Deposition of Oil-film:}

A $1 \%(w / v)$ solution of the oil was prepared in toluene (AR grade). The pre-cleaned SS-304 panels were dipped in this solution for 30 minutes, dried in air for 15 minutes and then stored in a dessicator. For smaller samples $(1 \mathrm{~cm} \times 1$ $\mathrm{cm}$ ), a stainless steel strainer was used in order to ensure uniform deposition of oil.

\section{Results and Discussion}

The different SS-304 samples, as described in Table 1, were characterized in-depth for their bulk and surface characteristics using various techniques. The first part deals with bulk characterization, followed by the surface characterization of SS-304 panels and dishes. Subsequently, the characterization of the oil-film deposited on the SS-304 surface is discussed.

\section{1) Bulk Characterisation:}

In this section, we shall discuss the results for crystal phase analysis, chemical composition and hardness data of bulk stainless steel.

\section{a) Crystal Phase Analysis:}

Crystal phase of the stainless steel sample was determined using X-ray Diffraction technique (XRD). The results obtained are summarized in Table 2, for stainless steel samples along with an Austenitic stainless steel reference sample with a standard chemical composition (70\% Fe, 19\% Cr, 11\% Ni). The Powder Diffraction File number for the standard sample is 33-397.

Comparison of lattice spacings ( $d$ values) and relative intensities $\left(I / I_{o}\right)$ of the three samples with the Austenitic SS samples indicates that SSPN has essentially identical $\mathbf{d}$ values, although there is some deviation in the relative intensity, which might be due to the different levels of impurities present, and also due to absence of $\mathrm{Mn}$ in the standard used for comparison. SSOP might have an additional phase along with Austenite, because there is a strong peak at $d=3.05 \AA$. For SSDN, although two peaks have been observed at $\mathrm{d}=2.07 \AA$ and $1.27 \AA$, the peak at $1.80 \AA$ is absent, indicating that this steel probably has a mixed phase of Austenite and an unidentified phase.

It is well known [9] [10] that variation in $\mathrm{Cr}$ and $\mathrm{Ni}$ in the $\mathrm{Fe}-\mathrm{Cr}$ (18) - $\mathrm{Ni}$ (8) system may lead to deviation from Austenite phase to mixed phases of Austenite, Martensite and Ferrite. It is observed from EDX analysis (Table 3) that the 
Table 2. Crystal phase analysis of stainless steel samples (XRD).

\begin{tabular}{|c|c|c|c|c|c|}
\hline Samples & \multicolumn{4}{|c|}{ Lattice Spacings and Relative Intensities } & Crystal Phase \\
\hline \multicolumn{6}{|c|}{ Standard SS-304 [PDF no. 33 - 397] } \\
\hline $\mathrm{d}(\AA)$ & 2.08 & 1.80 & 1.27 & - & Austenitic Steel \\
\hline $\mathrm{I} / \mathrm{I}_{\mathrm{o}}$ & 100.0 & 50.0 & 30.0 & - & $\mathrm{Cr}_{0.19} \mathrm{Fe}_{0.70} \mathrm{Ni}_{0.11}$ \\
\hline \multicolumn{6}{|c|}{ SSPN: } \\
\hline $\mathrm{d}(\AA)$ & 2.0803 & 1.8041 & 1.2746 & - & Austenite+ \\
\hline $\mathrm{I} / \mathrm{I}_{\mathrm{o}}$ & 100.0 & 67.6 & 87.1 & - & Unknown phase \\
\hline \multicolumn{6}{|c|}{ SSDN: } \\
\hline $\mathrm{d}(\AA)$ & 2.0708 & - & 1.2706 & - & Austenite+ \\
\hline $\mathrm{I} / \mathrm{I}_{\mathrm{o}}$ & 100.0 & - & 67.7 & - & Unknown phase \\
\hline \multicolumn{6}{|c|}{ SSOP: } \\
\hline $\mathrm{d}(\AA)$ & 2.0735 & 1.7940 & 1.2694 & 3.0502 & Austenite+ \\
\hline $\mathrm{I} / \mathrm{I}_{\mathrm{o}}$ & 100.0 & 47.1 & 25.8 & 65.0 & Unknown phase \\
\hline
\end{tabular}

Table 3. Bulk micro-chemical composition (weight \%) of stainless steel samples (EDX).

\begin{tabular}{ccccc}
\hline Sample & Fe & Cr & Ni & Mn \\
\hline Standard SS-304* & $70.8-66.3$ & $18.0-20.0$ & $8.0-10.5$ & 2.0 \\
Sample - 1 & 70.81 & SSPN & & \\
Sample - 2 & 71.44 & 17.62 & 8.15 & 3.41 \\
& & SSDN & 7.41 & 3.31 \\
Sample - 1 & 74.02 & 14.00 & 0.98 & 10.95 \\
Sample - 2 & 73.89 & 14.27 & 1.63 & 10.14 \\
& & & & \\
Sample - 1 & 70.91 & 17.61 & 8.73 & 2.75 \\
Sample - 2 & 71.11 & 17.59 & 9.28 & 3.03 \\
\hline
\end{tabular}

${ }^{*}$ J. Goldstein, D. E. Newbury et al., "Scanning Electron Microscopy and X-ray Microanalysis", $2^{\text {nd }}$ edition, Pub: Plenum Press, New York (1994).

sample SSDN has a lot of $\mathrm{Mn}$ and very low level of $\mathrm{Ni}$ in its composition and also slightly lower level of $\mathrm{Cr}$. This composition might be the cause of the deviation from the Austenite phase in SSDN. The origin of the strong peak at $\mathbf{d}=\mathbf{3 . 0 5}$ $\AA$ in case of SSOP, however, is not very clear.

\section{b) Bulk Chemical Composition:}

Bulk chemical composition of the samples was studied using Energy Dispersive X-ray Spectrometry (EDX). Table 3 shows the chemical composition data for 3 sets of panels, along with the standard SS-304 composition, determined by EDX technique. A comparative analysis of the data shows that except new dishes (SSDN) all other samples have similar bulk chemical composition and all con- 
form to the standard chemical composition of SS-304 grade composition [11]. The sample SSDN shows a marked deviation from standard specification, where a major part of $\mathrm{Ni}$ has been replaced by $\mathrm{Mn}$.

Ni helps to stabilize the Austenite structure, and also enhances the mechanical properties and corrosion resistance. Higher level of Mn leads to the formation of a relatively harder steel and the ductility is also reduced considerably. Total replacement of $\mathrm{Ni}$ by $\mathrm{Mn}$, however, is not practical [12].

Figure 1 shows the composition of three typical samples-SSPN, SSDN and SSOP along with the standard SS-304 composition. From this data, it is evident that there is also a slight reduction in $\mathrm{Cr}$ percentage in SSDN. Characteristic EDX spectra are shown in Figures 2(a)-(c).

\section{c) Hardness Data:}

Micro-hardness values of the SS-304 panels were measured using Vickers indentor, with an applied load of $10 \mathrm{~kg}$. The values were found to be $185 \mathrm{HV}$ for SSPN and $206 \mathrm{HV}$ for SSDN. The higher value for SSDN as compared to SSPN can be attributed to higher Mn content in SSDN as discussed above in the chemical composition of the samples. The values are summarized in Table 4.

\section{2) Surface Characterisation}

The characterization of surface begins with the determination of morphology of the SS-304 surface by SEM and AFM, followed by the determination of the surface roughness using Profilometry. In the next phase, XPS technique has been used to establish the chemical identity, oxidation state and chemical composition of the elements present on the surface.

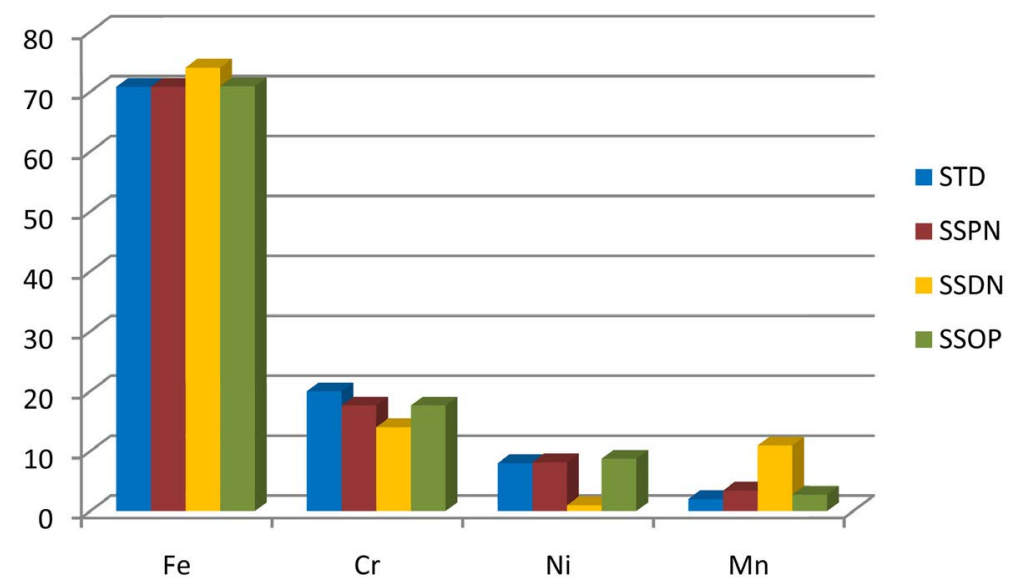

Figure 1. Micro-chemical composition of SS-304 samples.

Table 4. Micro-Hardness Values (HV) of stainless steel samples by Vicker's indentation technique.

\begin{tabular}{cc}
\hline Sample & Vicker's Hardness $\left(\mathrm{HV}^{*}\right)$ \\
\hline SSPN & $185 \mathrm{HV}$ \\
SSDN & $206 \mathrm{HV}$ \\
\hline
\end{tabular}

Applied load $=10 \mathrm{~kg} ;{ }^{*} 1 \mathrm{HV}=1 \mathrm{~kg} \cdot \mathrm{mm}^{-2}=9.8 \mathrm{MPa}$. 


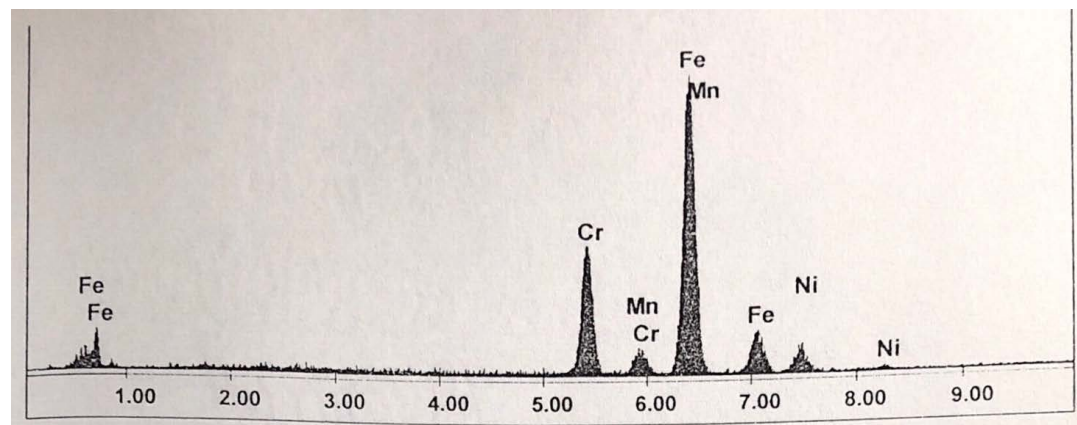

(a)

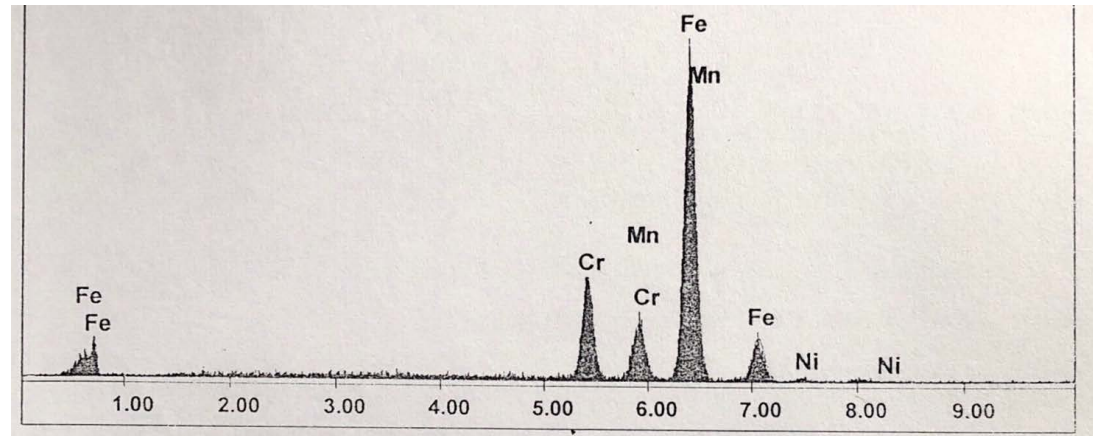

(b)

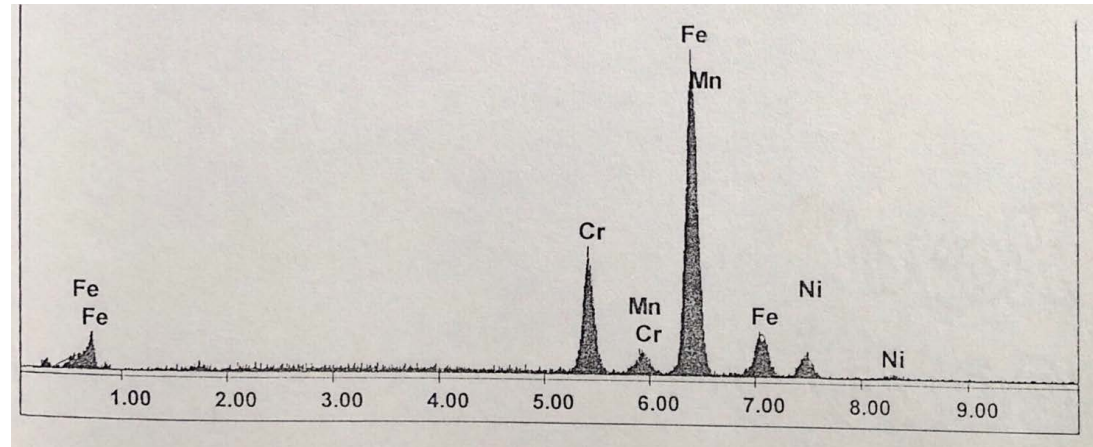

(c)

Figure 2. (a) EDX spectrum of SSPN; (b) EDX spectrum of SSDN; (c) EDX spectrum of SSOP.

\section{a) Surface Morphology:}

Surface morphology of SS-304 has been studied using Scanning Electron Microscopy (SEM) and Atomic Force Microscopy (AFM) techniques.

i) SEM: It is very interesting to know that when studied on a sufficiently fine scale, the surfaces of even the most highly polished engineering components show irregularities appreciably larger than atomic dimensions.

The SEM micrographs of representative samples of SSPN, SSDN and SSOP are shown in Figures 3(a)-(c) respectively. It is quite evident from these micrographs that new panel (SSPN) and dishes (SSDN) are reasonably smooth with fine rolling marks and occasional defects or scratches. The rolling marks are a result of the buffing or polishing process undergone by the stainless steel surface [13]. 


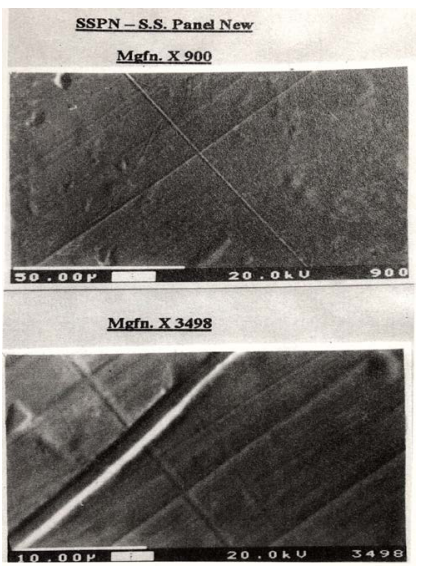

(a)

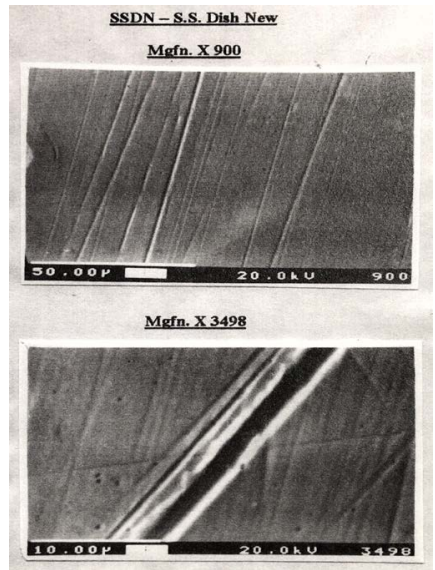

(b)

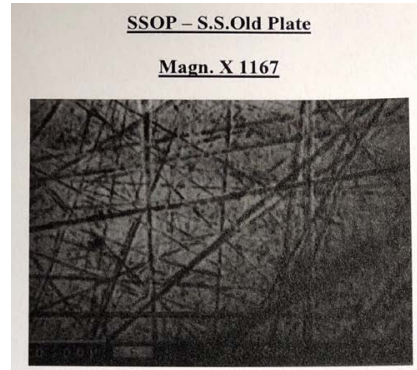

SSOP-S.S.Old Plate

$\underline{\text { Magn. X } 1500}$

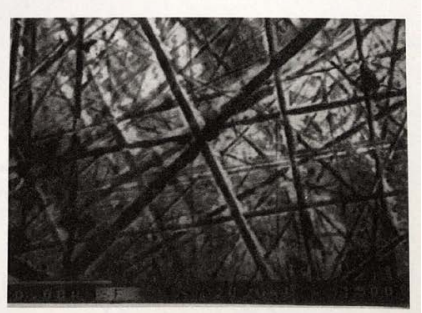

(c)

Figure 3. (a) SEM micrographs of SSPN; (b) SEM micrographs of SSDN; (c) SEM micrographs of SSOP. 
The morphology of the used old plates (SSOP) shows that the surface is quite rough with lot of scratches of variable dimensions distributed in a random fashion all over the surface. The average width of the scratches for old sample has been calculated manually from the micrographs and the value is found to be $1.075 \mu \mathrm{m}$ for a 15 year old sample which has been used in this study as a representative old sample. A large number of scratches were manually measured on magnified SEM micrographs and a statistical average of the readings was then determined using MS excel. The important morphological characteristics as revealed by SEM technique are summarized in Table 5 .

The damage that the surface undergoes with usage is clearly highlighted by these micrographs. It is evident that a brand new surface that has fine unidirectional rolling marks before usage becomes very rough and shows random marks or scratches of wide dimensions on continued usage.

ii) AFM: AFM technique has been used in the present work to study the three-dimensional surface morphology with high resolution.

Figure 4 shows the AFM micrographs of SSPN and SSOP respectively. The results obtained support the SEM observations, strongly highlighting the differences in the surface roughness as seen, for SSPN and SSOP samples. The major advantage of using this technique, however, lies in the three-dimensional mapping of the surface morphology with characteristic hills and valleys as observed for old sample SSOP compared with two-dimensional SEM micrographs.

\section{b) Surface Roughness:}

Surface roughness of the SS-304 samples has been measured with a profilometer, in which a fine stylus travels over the surface under study, and its vertical displacement is recorded, giving a profile of the surface under study.

The values of the average roughness parameter $\left(R_{a}\right)$ measured by a fine tip profilometer are $0.025 \mu \mathrm{m}$ and $0.024 \mu \mathrm{m}$ for SSPN and SSDN respectively, while for SSOP the value was recorded as $0.153 \mu \mathrm{m}$, which is about 6 times higher compared to the new panels and dishes. The respective results along with the information obtained in the SEM technique are summarized in Table 5.

The 6-fold rise in the surface roughness values from new to old panels once again highlights the damage undergone by the surface on usage. This large increase in the value of the surface roughness plays a very important role in the reduction of the mirror-like shine of brand new panels.

Table 5. Surface morphology (SEM) and average Roughness $\left(\mathrm{R}_{\mathrm{a}}\right)$ measurements.

\begin{tabular}{|c|c|c|}
\hline Samples & Surface Morphology by SEM & $\begin{array}{l}\text { Average Roughness } \\
\mathbf{R}_{\mathrm{a}}(\mu \mathrm{m}) \text { by Profilometer }\end{array}$ \\
\hline SSPN & $\begin{array}{l}\text { Smooth surface with very fine rolling marks } \\
\text { aligned in one direction and parallel to each other }\end{array}$ & 0.025 \\
\hline SSDN & $\begin{array}{l}\text { Smooth surface with very fine rolling marks } \\
\text { aligned in one direction and parallel to each other }\end{array}$ & 0.024 \\
\hline SSOP & $\begin{array}{l}\text { Rough surface with a lot of scratches. } \\
\text { Average scratch width }=1.075 \mu \mathrm{m} \\
\text { [Min. width } \sim 0.2425 \mu \mathrm{m}, \text { Max. width } \sim 3.341 \mu \mathrm{m} \text { ] }\end{array}$ & 0.153 \\
\hline
\end{tabular}




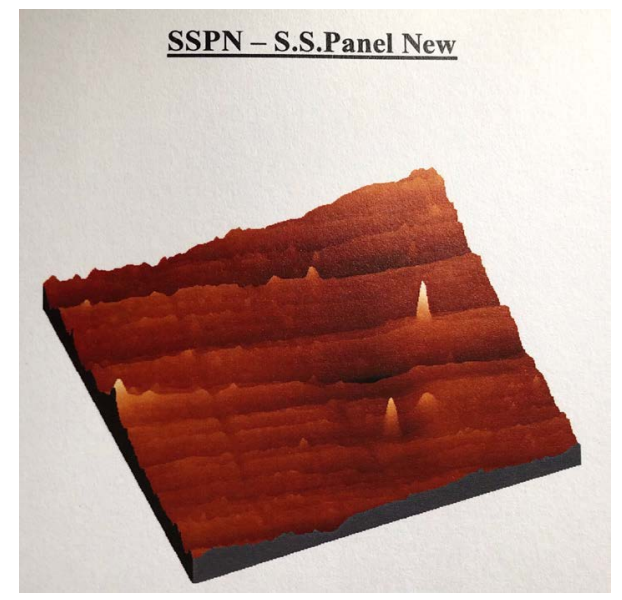

(a)

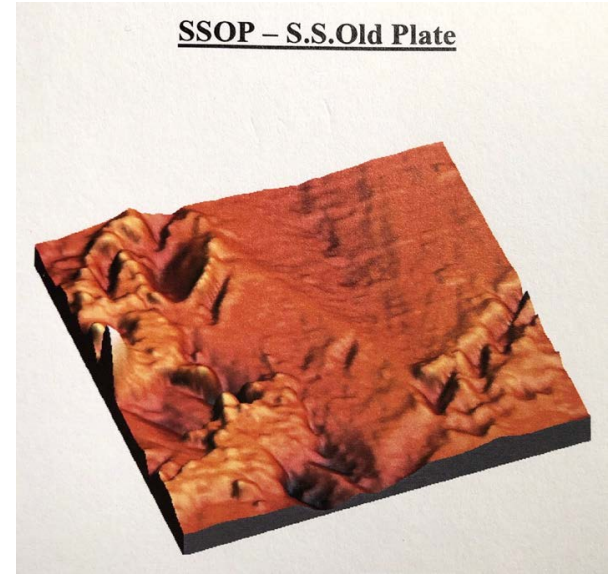

(b)

Figure 4. AFM Micrographs of SSPN and SSOP.

\section{c) Surface Analysis of SS-304 Samples:}

Surface analysis of the SS-304 samples was carried out using X-ray Photoelectron Spectroscopy (XPS) [14]. The technique is based on the excitation of the core electrons of the sample atom by the incident X-rays, i.e. $\mathrm{Mg} \mathrm{Ka} \mathrm{X}$-rays $(1253.6 \mathrm{eV})$ in this case [14] [15] [16].

The binding energy values (B.E) of the electrons are representative of the atoms from which these electrons are ejected (chemical identity), whereas the intensity is proportional to the quantity of the element present (surface chemical composition). The oxidation state of the elements is determined from the shift in B.E. values of the respective elements.

The extended XPS spectra of SSPN, SSDN and SSOP samples are shown in Figures 5(a)-(c) respectively. The results clearly show that the major elements present in the bulk phase are also present in the surface region, except for the sample SSPN. For this sample, the presence of $\mathrm{Ni}$ is not detected in the surface region, although it is present at about $8 \%$ in the bulk phase. For SSDN and SSOP, however, the major elements that are present in the bulk phase, i.e. $\mathrm{Fe}, \mathrm{Cr}$, $\mathrm{Mn}$ for SSDN and $\mathrm{Fe}, \mathrm{Cr}, \mathrm{Ni}$ for SSOP are also detected in the surface region. 


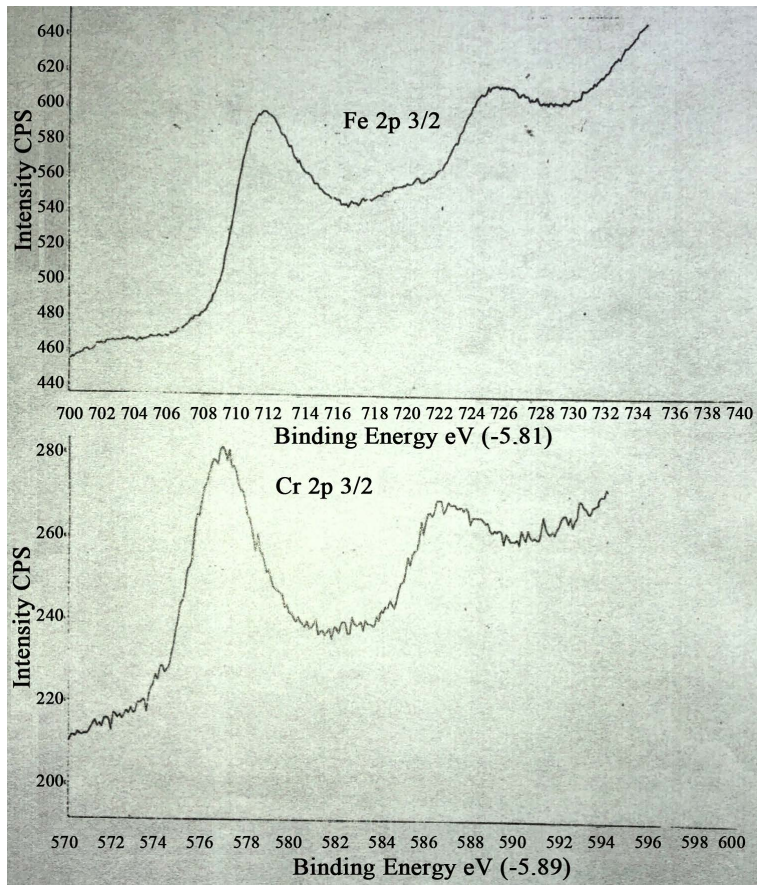

(a)

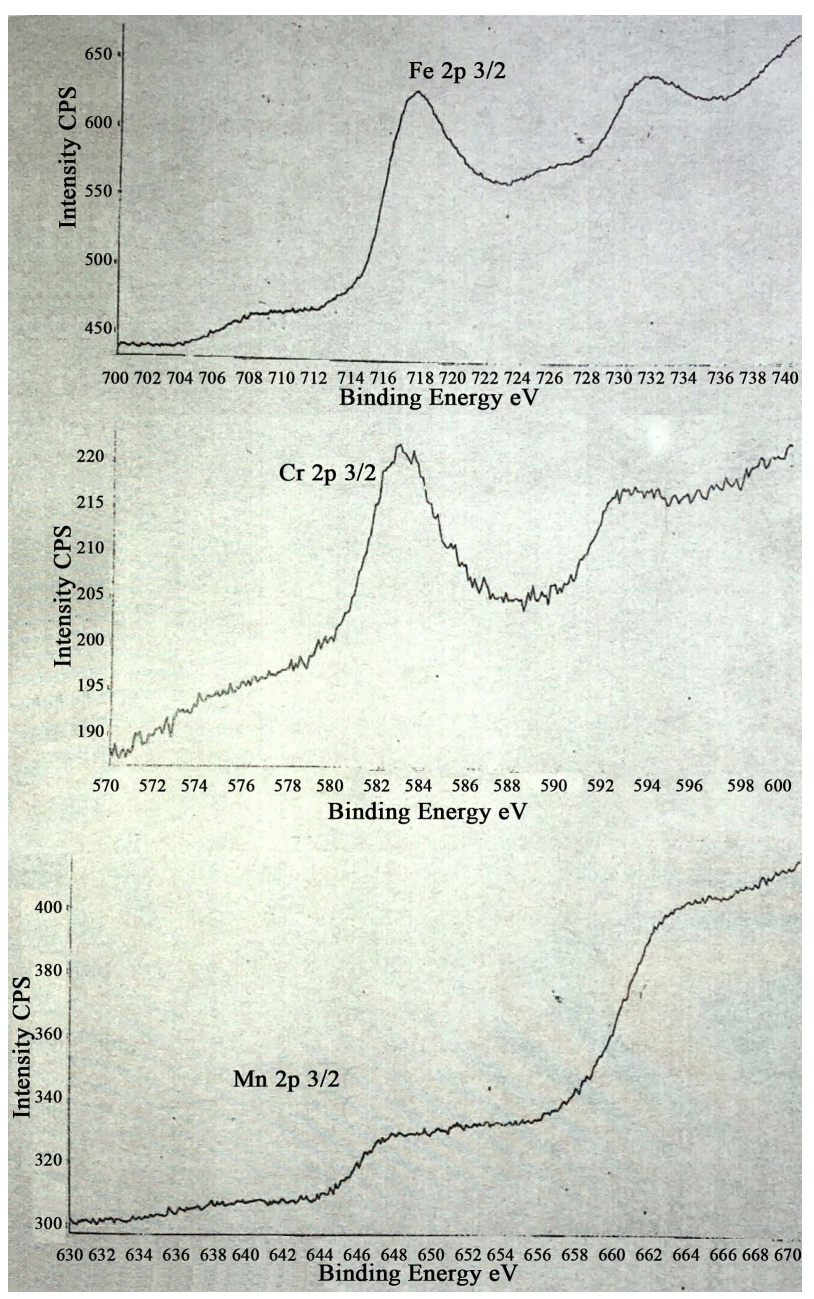

(b) 


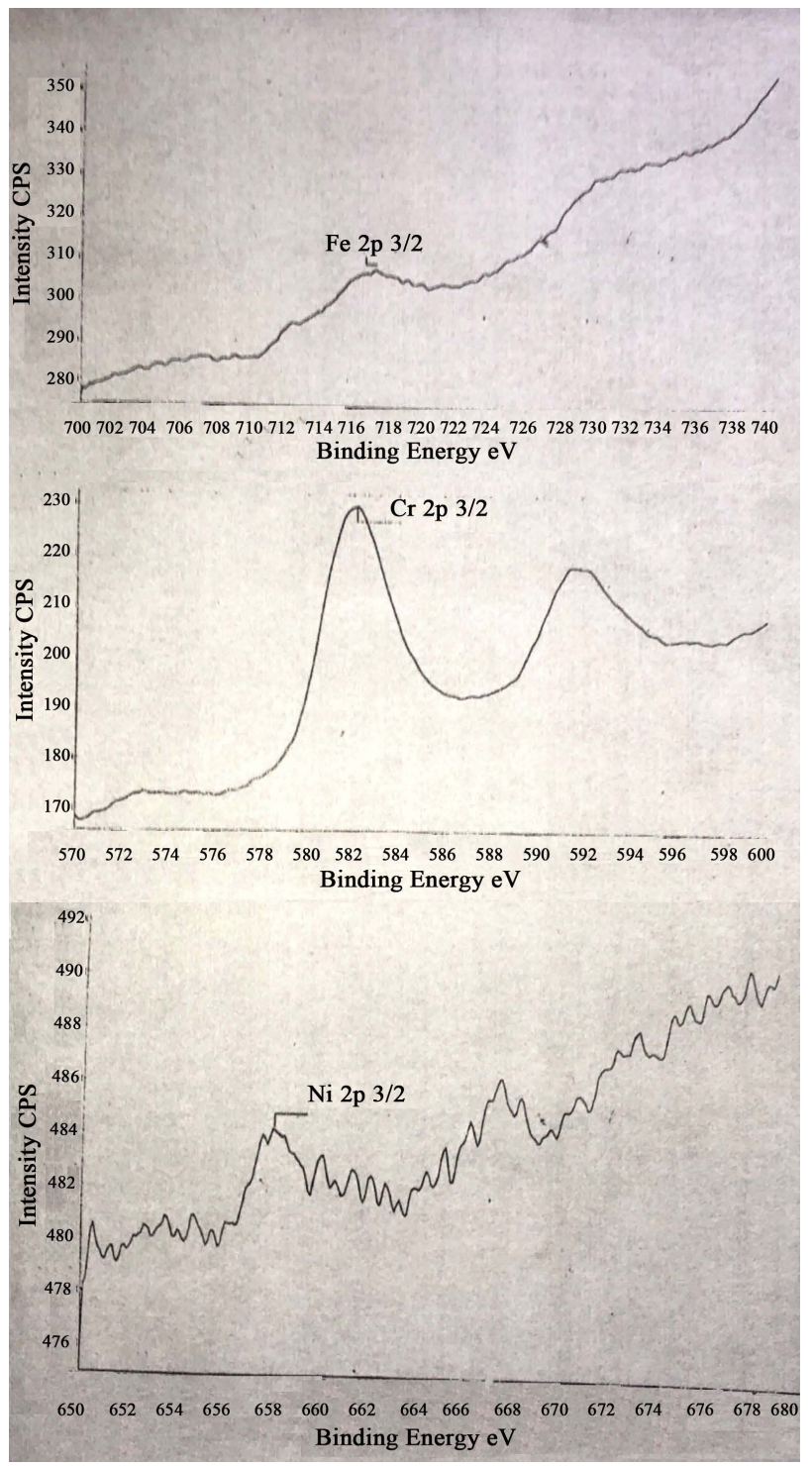

(c)

Figure 5. Extended XPS spectra of (a) SSPN; (b) SSDN; (c) SSOP.

The minor component $\mathrm{Ni}$ for SSDN and Mn for SSOP is not detected in any of these samples. The measured B.E. values of Fe 2 $\mathrm{p}_{3 / 2}, \mathrm{Cr} 2 \mathrm{p}_{3 / 2}, \mathrm{Ni} 2 \mathrm{p}_{3 / 2}, \mathrm{Mn}$ $2 \mathrm{p}_{3 / 2}$, C 1s and $\mathrm{O} 1 \mathrm{~s}$ of stainless steel samples, along with the shift in B.E. values compared with normal metallic states, are summarized in Table 6.

The shift in the B.E. values of Fe $2 \mathrm{p}_{3 / 2}(4.4 \mathrm{eV}), \mathrm{Cr} 2 \mathrm{p}_{3 / 2}(2.8 \mathrm{eV}), \mathrm{Ni} 2 \mathrm{p}_{3 / 2}(\sim 1.0$ $\mathrm{eV}), \mathrm{Mn} 2 \mathrm{p}_{3 / 2}(3.0 \mathrm{eV})$ electron levels from their respective metallic state indicates that these elements are present on the surface in the form of their oxides. In order to carry out quantitative composition analysis, we need the peak areas of $2 \mathrm{p}_{3 / 2}$ electron levels of each of the four elements, viz. $\mathrm{Fe}, \mathrm{Cr}, \mathrm{Ni}$ and $\mathrm{Mn}$ and the corresponding photoelectric cross section (P.E.C.S.) of each of the elements. The peak areas of the $2 \mathrm{p}_{3 / 2}$ electron levels have been calculated from the extended spectra of each of the elements and the photoelectric cross-sections of 
Table 6. Binding energy of electrons for different elements of stainless steel samples (XPS).

\begin{tabular}{ccccccc}
\hline \multirow{2}{*}{ Sample } & \multicolumn{7}{c}{ Binding Energies in $\mathrm{eV}$} \\
\cline { 2 - 7 } & $\mathrm{Fe} 2 \mathrm{p}_{3 / 2}$ & $\mathrm{Cr} 2 \mathrm{p}_{3 / 2}$ & $\mathrm{Ni} 2 \mathrm{p}_{3 / 2}$ & $\mathrm{Mn} 2 \mathrm{p}_{3 / 2}$ & $\mathrm{C} 1 \mathrm{~s}$ & $\mathrm{O} 1 \mathrm{~s}$ \\
\hline SSPN & 711.2 & 576.9 & - & - & 285.0 & $530,532.3$ \\
SSDN & 711.4 & 576.8 & - & 641.8 & 285.0 & 530.4 \\
SSOP & 710.9 & 577.2 & 853.1 & - & 285.0 & 531.7 \\
\hline & \multicolumn{7}{c}{ Shift in Binding Energies in $\mathrm{eV}$} \\
Sample & $\mathrm{Fe} 2 \mathrm{p}_{3 / 2}$ & $\mathrm{Cr} 2 \mathrm{p}_{3 / 2}$ & $\mathrm{Ni} 2 \mathrm{p}_{3 / 2}$ & $\mathrm{Mn} 2 \mathrm{p}_{3 / 2}$ & $\mathrm{C} 1 \mathrm{~s}$ & $\mathrm{O} 1 \mathrm{~s}$ \\
\hline SSPN & 4.4 & 2.8 & - & - & 0.0 & $0.0,2.3$ \\
SSDN & 4.6 & 2.7 & - & 3.0 & 0.0 & 0.4 \\
SSOP & 4.1 & 3.1 & 0.8 & - & 0.0 & 1.7 \\
\hline
\end{tabular}

each of the four elements have been taken from literature. Next, we have calculated the ratios of peak areas and the corresponding photoelectric cross-sections. The results are summarized in Table 7 .

Finally, for a meaningful comparison of surface and bulk composition, we have tabulated the values of the ratios of $\mathrm{Cr} / \mathrm{Fe}, \mathrm{Ni} / \mathrm{Fe}$ and $\mathrm{Mn} / \mathrm{Fe}$ in the surface region along with the corresponding bulk ratios in Table 8. It is quite evident from these data that there is about $24 \%$ enhancement in $\mathrm{Cr} / \mathrm{Fe}$ in the surface layer compared with their bulk values, in both new dish and new panels. For the old sample, there is a huge increase in $\mathrm{Cr} / \mathrm{Fe}$ ratio, which is difficult to explain. This may be attributed partly to a very weak Fe signal (about $1 / 4^{\text {th }}$ compared with SSPN) from this sample, while the signal intensity of $\mathrm{Cr}$ is about double compared with SSPN as is evident in Table 6. For Mn and Ni elements, no such increase is observed in the surface layers. In fact there is slight reduction in their concentration in the surface region, compared with the bulk values. The $\mathrm{Cr}$ enrichment of the surface region of SS-304 has been reported by other workers as well [1] [17] [18].

\section{3) Characterization of SS-304 Surface with a Thin Organic Film:}

In order to study the effect of a thin adsorbed oil-film on the appearance characteristics of SS-304 surface, a thin film of sunflower oil in toluene was deposited, as described in the experimental Section (b). The deposited oil-film was characterized using techniques like XPS and Reflection-FTIR in order to understand the type of bonding between the substrate and the film and finally how the presence of the film modifies the reflectance and gloss values of the SS-304 surface.

\section{a) Surface Study by XPS:}

As discussed in the previous section, XPS is a very useful technique in the identification of surface species. This technique has been used to study the nature of bonding of the adsorbed oil-film on the SS-304 surface. A comparative 
Table 7. Peak areas and peak area/P.E.C.S. ratios for stainless steel samples (XPS).

\begin{tabular}{|c|c|c|c|c|c|}
\hline Sample & Parameter & $\mathrm{Fe} 2 \mathrm{p}_{3 / 2}$ & $\operatorname{Cr} 2 \mathrm{p}_{3 / 2}$ & $\mathrm{Ni} 2 \mathrm{p}_{3 / 2}$ & $\operatorname{Mn} 2 \mathrm{p}_{3 / 2}$ \\
\hline & P.E.C.S. & 10.54 & 7.60 & 13.92 & 8.99 \\
\hline \multirow[t]{2}{*}{ SSPN } & Peak Area & 493,695 & 110,442 & - & - \\
\hline & Peak area/P.E.C.S. & 46,840 & 14,532 & - & - \\
\hline \multirow[t]{2}{*}{ SSDN } & Peak Area & 505,979 & 86,448 & - & 54,277 \\
\hline & Peak area/P.E.C.S. & 48,006 & 11,375 & - & 6037 \\
\hline \multirow[t]{2}{*}{ SSOP } & Peak Area & 84,661 & 227,441 & 11949 & - \\
\hline & Peak area/P.E.C.S. & 8032 & 29,926 & 858 & - \\
\hline
\end{tabular}

Table 8. Metallic component ratios on the surface and in the bulk for stainless steel samples (XPS).

\begin{tabular}{ccccc}
\hline Sample & Ratio & $\mathrm{Cr} / \mathrm{Fe}$ & $\mathrm{Ni} / \mathrm{Fe}$ & $\mathrm{Mn} / \mathrm{Fe}$ \\
\hline SSPN & Surface & 0.310 & - & - \\
& Bulk & 0.250 & - & - \\
\multirow{2}{*}{ SSDN } & Surface & 0.237 & - & 0.126 \\
& Bulk & 0.191 & - & 0.143 \\
SSOP & Surface & 3.726 & 0.107 & - \\
& Bulk & 0.250 & 0.128 & - \\
\hline
\end{tabular}

analysis of the XPS results has been carried out for the SS-304 surface with and without the oil-film, in order to learn more about the interaction of the film with the substrate.

Table 9 summarizes the results obtained from four samples, viz. SSPN and SSDN, with and without the oil-film. The survey spectra in Figure 6(a) and Figure 6(b) clearly shows that the signals from the metallic elements are totally absent in SSPO and SSDO $(560 \mathrm{eV}-730 \mathrm{eV})$, indicating that the metal surface is uniformly covered with an organic film. Additional support for this conclusion comes from the XPS results of clean glass surface and glass surface with oil-film (Figure 6(c)).

Further confirmation is obtained from the extended spectra of $\mathrm{C}$ 1s (Figure 6(d)), which shows the presence of two clear C 1s peaks at B.E. $285.0 \mathrm{eV}$ and $289.3 \mathrm{eV}$ respectively. The peak at $285.0 \mathrm{eV}$ comes from the hydrocarbon contamination from the environment, which is always present in an XPS spectrum. The C 1s peak at higher B.E., i.e. $289.3 \mathrm{eV}$ indicates the presence of a second C species on the surface and this may be attributed to $\mathrm{C}$ in the oil-film. The $\mathrm{O} 1 \mathrm{~s}$ B.E. at $533.1 \mathrm{eV}$ (Figure 6(e)) may probably be attributed to $\mathrm{O}$ atoms in the oil. (An exact assignment will require the deconvolution of the broad $\mathrm{O}$ peak into two components, one coming from the substrate and the other from the oil.) From all these data, it may be concluded that the thin film of oil deposited completely covers the metal surface and adsorption of oil on the metal surface is a 


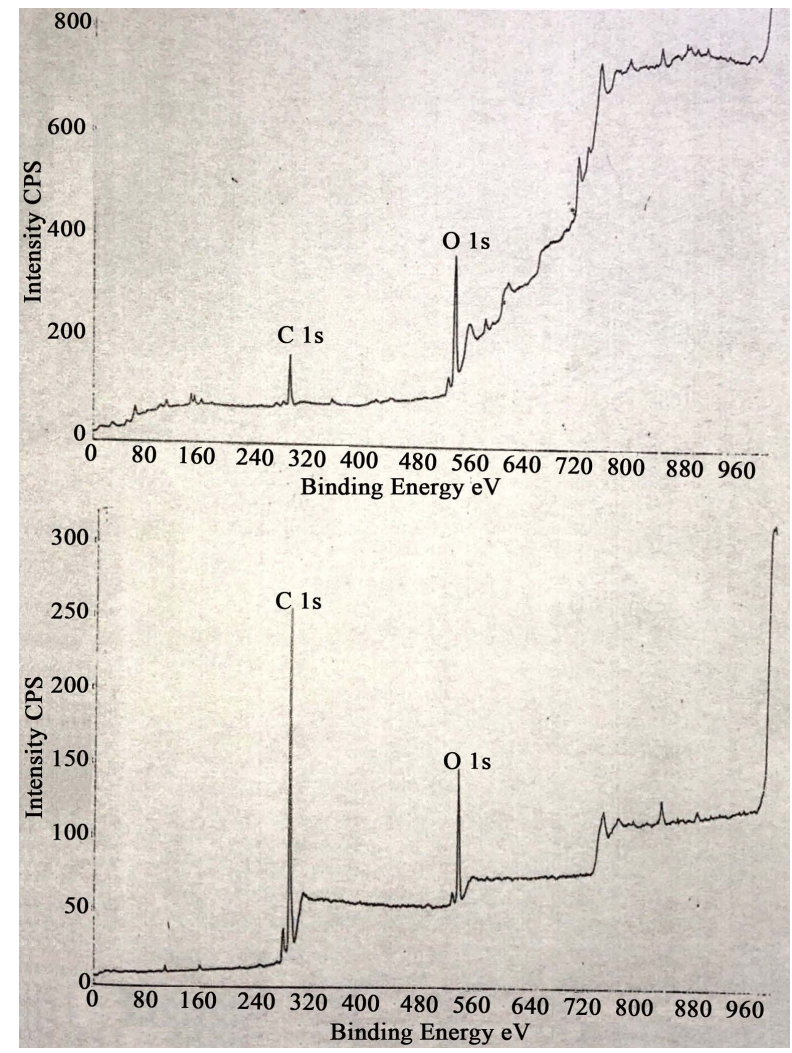

(a)
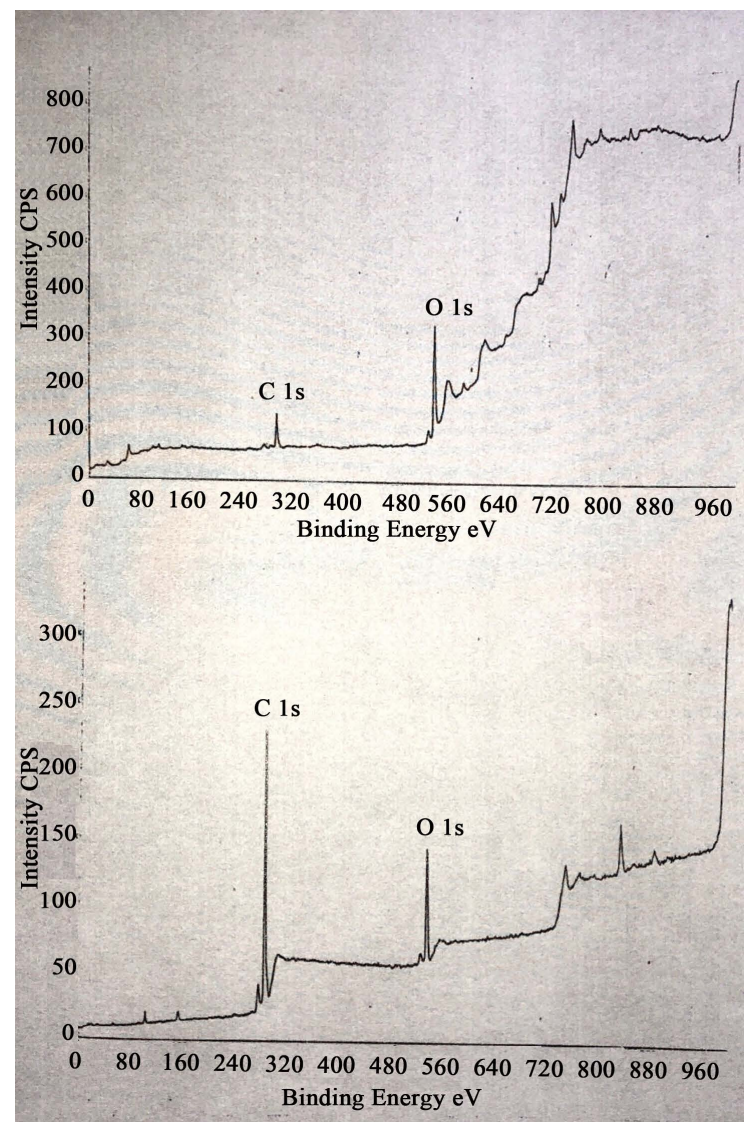

(b) 


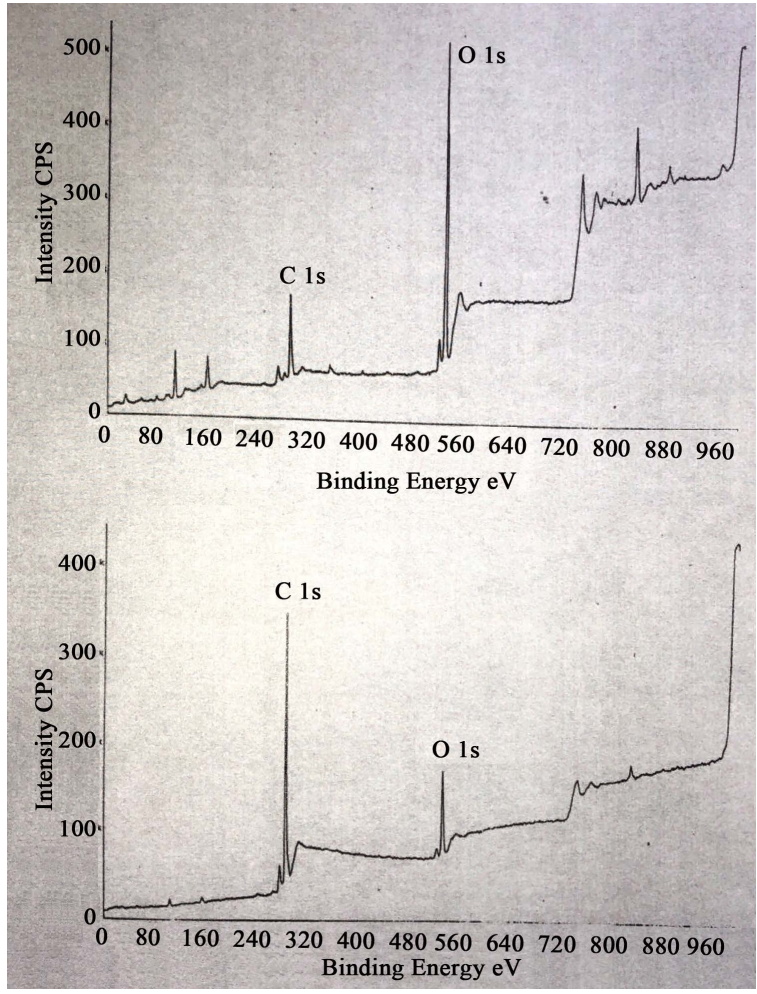

(c)

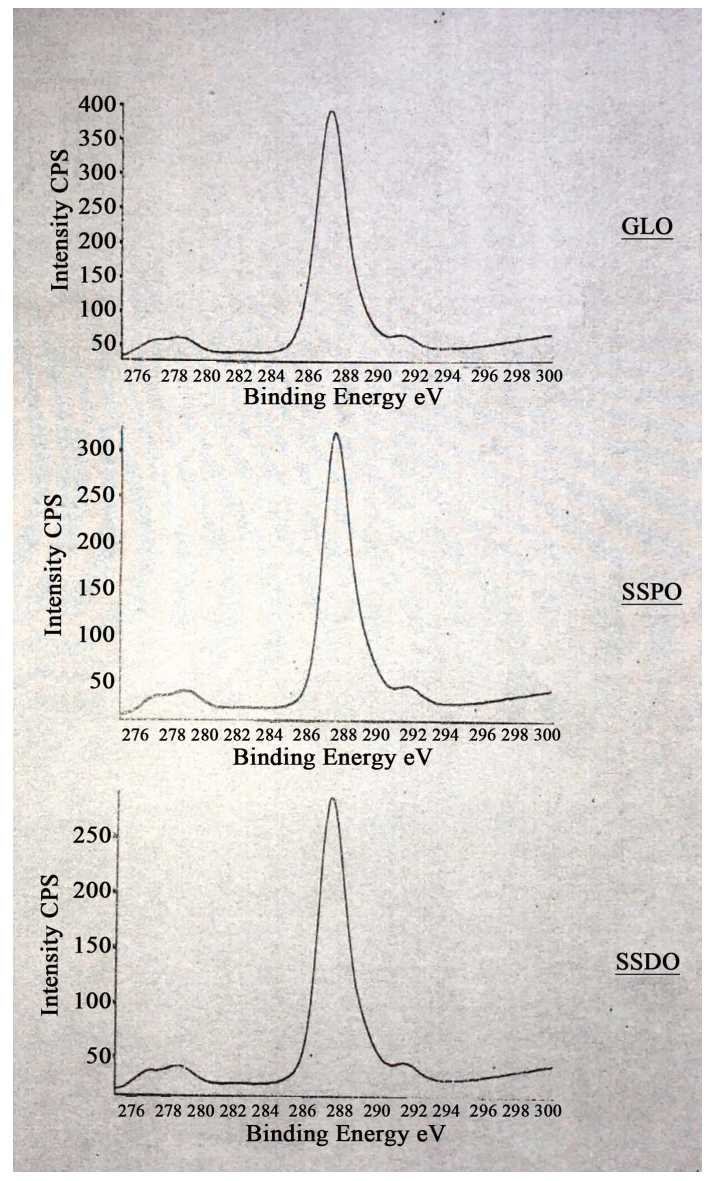

(d) 


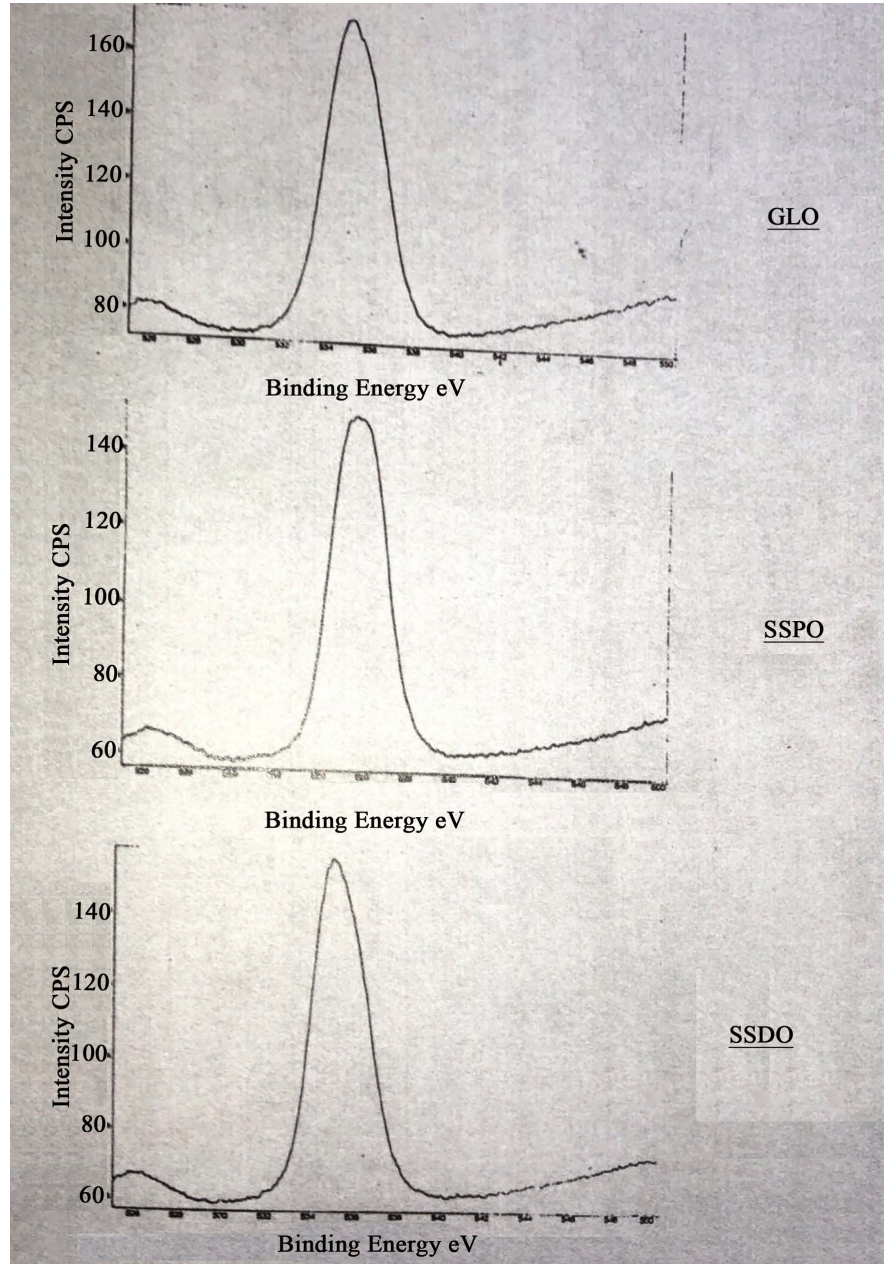

(e)

Figure 6. XPS Survey Spectra for: (a) SSPN and SSPO; (b) SSDN and SSDO; (c) GLC and GLO; (d) C-1s on different substrates with oil-film; (e) O-1s on different substrates with oil-film.

Table 9. Binding energy of electrons of different elements for stainless steel samples with and without oil film (XPS).

\begin{tabular}{|c|c|c|c|c|c|c|}
\hline \multirow{2}{*}{ Sample } & \multicolumn{6}{|c|}{ Binding Energies in eV } \\
\hline & $\mathrm{Fe} 2 \mathrm{p}_{3 / 2}$ & $\mathrm{Cr} 2 \mathrm{p}_{3 / 2}$ & $\mathrm{Ni} 2 \mathrm{p}_{3 / 2}$ & $\operatorname{Mn} 2 \mathrm{p}_{3 / 2}$ & $\mathrm{C} 1 \mathrm{~s}$ & O 1s \\
\hline SSPN & 711.2 & 576.9 & - & - & 285.0 & $530,532.3$ \\
\hline SSPO & - & - & - & - & $285.0,289.3$ & 533.1 \\
\hline SSDN & 711.4 & 576.8 & - & 641.8 & 285.0 & 530.4 \\
\hline SSDO & - & - & - & - & $285.0,289.1$ & 532.6 \\
\hline GLC & - & - & - & - & 285.0 & 532.4 \\
\hline GLO & - & - & - & - & $285.0,289.2$ & 532.8 \\
\hline
\end{tabular}

GLC: Glass Chemically Cleaned; GLO: Glass with Oil-film.

purely physical phenomenon. This is further confirmed by Reflection-FTIR study of the same set of steel samples.

\section{b) Reflection-FTIR:}


Reflection-FTIR is a technique used to study the vibrational spectra of species adsorbed on a surface, where the sample is scanned at a grazing angle. SS-304 panels with the oil-film were studied using this technique for identifying the chemical reactions occurring on the surface. Any chemical change undergone will give rise to a new peak in the FTIR spectrum, and can therefore be easily detected and identified with the help of the position of the peak in the spectrum, as each vibrational peak is associated with a particular functional group.

Initially, the bulk oil was characterized using FTIR technique and the characteristic vibrational spectrum is shown in Figure 7(a). The FTIR spectrum for the adsorbed oil-film on SS-304 surface is shown in Figure 7(b). A comparison of the two spectra reveals essentially identical features. The absence of any shifts in the peak positions clearly indicates that the film is only physically adsorbed on the surface and there is no chemical change involved. Each of the vibrational peaks in the spectra has been assigned to the corresponding functional groups of the oil molecule, as shown in Table 10(a). For the sake of comparison, a reference table has been incorporated, detailing the FTIR data for sunflower oil, confirming the main characteristic absorption bands displayed in the spectrum of bulk oil (Table 10(b)) [19] [20].

Table 10. (a) FTIR results for bulk oil and oil film on stainless steel panels; (b) Main characteristic absorption bands as displayed in the FTIR spectrum of sunflower oil.

(a)

\begin{tabular}{cccc}
\hline \multirow{2}{*}{ Functional Group } & Mode of Vibration & \multicolumn{2}{c}{ Wave number and Intensity } \\
\cline { 3 - 4 } & & Bulk Oil & SSPN + Oil \\
\hline -C-H & Stretching & $3008.53(\mathrm{~S})$ & - \\
$-\mathrm{C}-\mathrm{H}\left(\mathrm{CH}_{2}\right)$ & Stretching (asymmetric) & $2924.58(\mathrm{~S})$ & $2937.9(\mathrm{~S})$ \\
$-\mathrm{C}-\mathrm{H}\left(\mathrm{CH}_{2}\right)$ & Stretching (symmetric) & $2853.53(\mathrm{~S})$ & $2861.3(\mathrm{~S})$ \\
$-\mathrm{C}=\mathrm{O}($ ester$)$ & Stretching & $1746.41(\mathrm{~S})$ & $1748.1(\mathrm{~S})$ \\
$-\mathrm{C}=\mathrm{C}(\mathrm{cis})$ & Stretching & $1650.60(\mathrm{~W})$ & - \\
$-\mathrm{C}-\mathrm{H}\left(\mathrm{CH}_{2}-\mathrm{CH}_{3}\right)$ & Bending (scissoring) & $1463.59(\mathrm{M})$ & $1467.2(\mathrm{M})$ \\
$-\mathrm{C}-\mathrm{H}\left(\mathrm{CH}_{3}\right)$ & Bending (symmetric) & $1377.61(\mathrm{~W})$ & - \\
$-\mathrm{C}-\mathrm{O},>\mathrm{CH}_{2}$ & Stretching, Bending & $1161.52(\mathrm{M})$ & $1176.2(\mathrm{M})$ \\
$-\left(\mathrm{CH}_{2}\right)_{\mathrm{n}},-\mathrm{HC}=\mathrm{CH}(\mathrm{cis})$ & Bending (rocking) & $722.99(\mathrm{M})$ & $731.9(\mathrm{~S})$ \\
\hline
\end{tabular}

(b)

\begin{tabular}{ccc}
\hline Functional Group & Mode of Vibration & Wave number and Intensity \\
\hline$=\mathrm{C}-\mathrm{H}$ & Stretching & $3006(\mathrm{M})$ \\
$-\mathrm{C}-\mathrm{H}\left(\mathrm{CH}_{2}\right)$ & Stretching (asymmetric) & $2925(\mathrm{VS})$ \\
$-\mathrm{C}-\mathrm{H}\left(\mathrm{CH}_{2}\right)$ & Stretching (symmetric) & $2855(\mathrm{VS})$ \\
$-\mathrm{C}=\mathrm{O}($ ester$)$ & Stretching & $1746(\mathrm{VS})$ \\
$-\mathrm{C}=\mathrm{C}(\mathrm{cis})$ & Stretching & $1650(\mathrm{VS})$ \\
$-\mathrm{C}-\mathrm{H}\left(\mathrm{CH}_{2}-\mathrm{CH}_{3}\right)$ & Bending (scissoring) & $1465(\mathrm{M})$ \\
$-\mathrm{C}-\mathrm{O},>\mathrm{CH}$ & Stretching, Bending & $1165(\mathrm{~S})$ \\
$-\left(\mathrm{CH}_{2}\right)_{\mathrm{n}},-\mathrm{HC}=\mathrm{CH}(\mathrm{cis})$ & Bending (rocking) & $725(\mathrm{M})$ \\
\hline
\end{tabular}




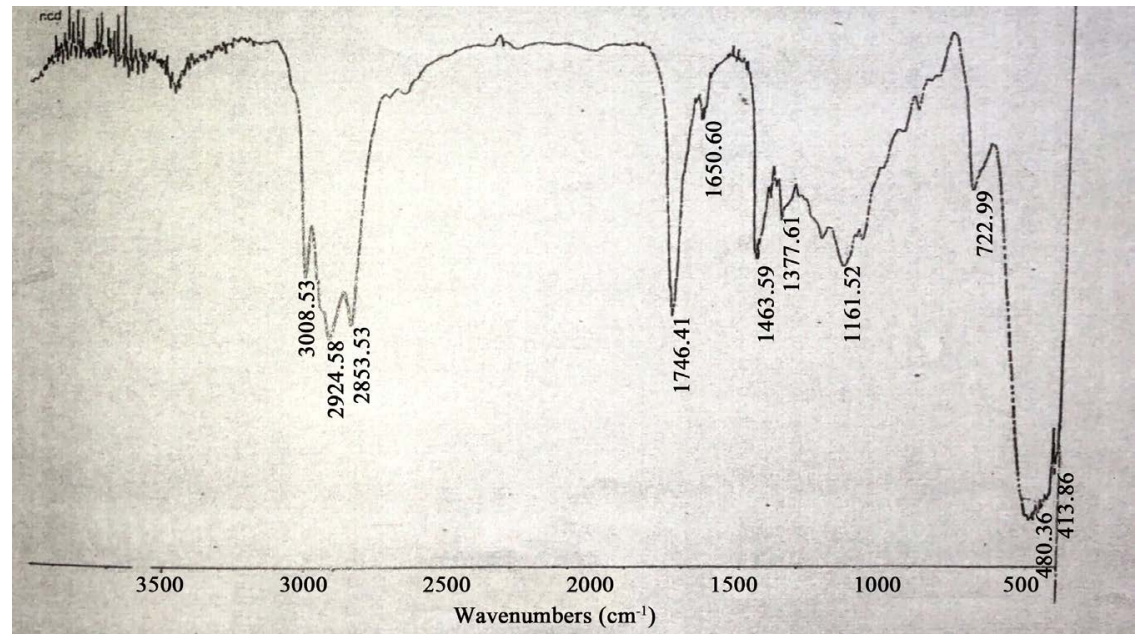

(a)

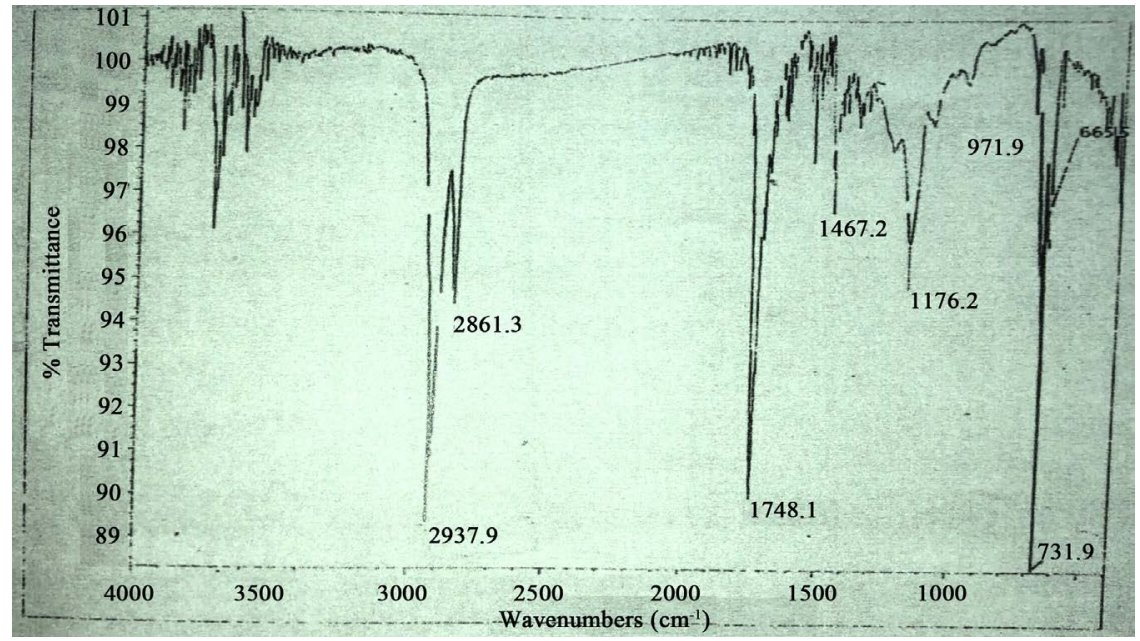

(b)

Figure 7. FTIR spectra for (a) bulk Oil; (b) adsorbed oil-film on SS-304 (SSPO).

\section{4) Appearance Measurements of SS-304 Surface:}

It is well known from the mechanism of appearance that for a metallic surface the dominant mode of light distribution is specular reflection, which determines the glossiness and chromaticness of the surface, while the diffuse reflection determines the reflection haze [21]. Since the reflection of light from most real surfaces is neither completely specular nor completely diffuse, it is important to measure both the components accurately. In the present work, Reflectance Spectrophotometer in the visible region (4000 $\AA 7000 \AA$ ) has been used for the measurement of specular and diffuse components of reflected light. A Glossmeter has also been used for measurement of specular gloss at selected angles of incidence.

\section{a) Reflectance Spectrophotometer in the Visible Region:}

The instrument used for this purpose has an integrated sphere (D/8) geometry, which permits the measurement of both the total reflectance as well as the diffuse reflectance. The specular component is measured at the angle of $8^{\circ}$. All 
the reflectance measurements have been made using the small area view (SAV) mode, having the aperture dimensions of $10 \mathrm{~mm} \times 7.5 \mathrm{~mm}$.

The reflectance spectra of a set of six samples (SSPN, SSDN, SSOP, SSPO, $\mathrm{CPP}, \mathrm{CPU}$ ), measured in both Specular Component Included (SCI) and Specular Component Excluded (SCE) modes, are shown in Figure 8(a) \& Figure 8(b). Both specular and diffuse reflectance values at three different wavelengths, $\lambda=$ $4000 \AA$, $5500 \AA$ and $7000 \AA$ have been summarized in Tables 11(a)-(c) respectively. The reflectance values of specular and diffused components along with total reflectance are also plotted in Figure 8(c) $(\lambda=5500 \AA)$ and Figure 8(d) $(\lambda$ $=4000 \AA$ and $7000 \AA$ ).

Table 11. Specular and diffuse reflectance values at $8^{\circ}$ for SS-304 samples. (a) $\lambda=4000 \AA$; (b) $\lambda=5500 \AA$; (c) $\lambda=7000 \AA$.

(a)

\begin{tabular}{cccc}
\hline Sample & Specular & Diffuse & Total \\
\hline SSPN & 43.259 & 8.471 & 51.730 \\
SSDN & 44.746 & 2.111 & 46.857 \\
SSPO & 29.765 & 7.132 & 36.897 \\
SSOP & 8.509 & 27.604 & 36.113 \\
CPP & 34.948 & 9.424 & 44.372 \\
CPU & 1.198 & 29.285 & 30.483 \\
\hline
\end{tabular}

(b)

\begin{tabular}{cccc}
\hline Sample & Specular & Diffuse & Total \\
\hline SSPN & 52.175 & 7.902 & 60.077 \\
SSDN & 55.085 & 1.653 & 56.738 \\
SSPO & 49.201 & 5.559 & 54.760 \\
SSOP & 12.562 & 31.143 & 43.705 \\
CPP & 46.374 & 8.316 & 54.690 \\
CPU & 1.522 & 37.382 & 38.904 \\
\hline
\end{tabular}

(c)

\begin{tabular}{cccc}
\hline Sample & Specular & Diffuse & Total \\
\hline SSPN & 56.249 & 7.105 & 63.354 \\
SSDN & 59.091 & 1.320 & 60.411 \\
SSPO & 48.871 & 4.880 & 53.751 \\
SSOP & 15.915 & 31.388 & 47.303 \\
CPP & 51.818 & 7.057 & 58.875 \\
CPU & 1.856 & 40.900 & 42.756 \\
\hline
\end{tabular}




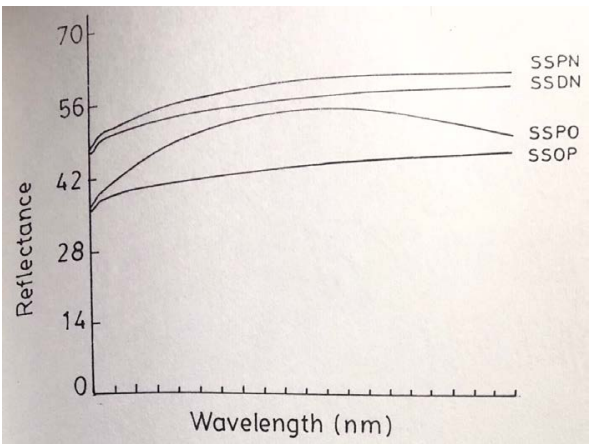

(a)

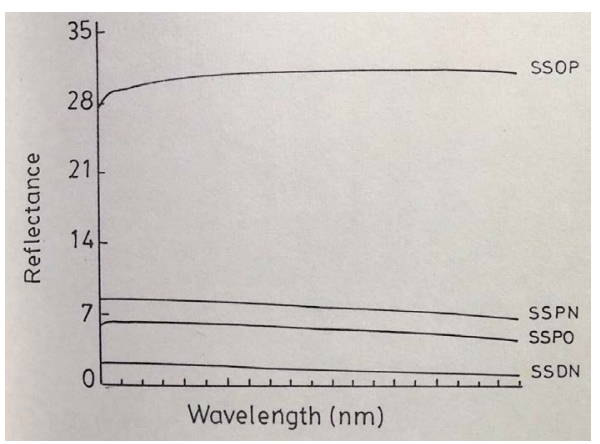

(b)

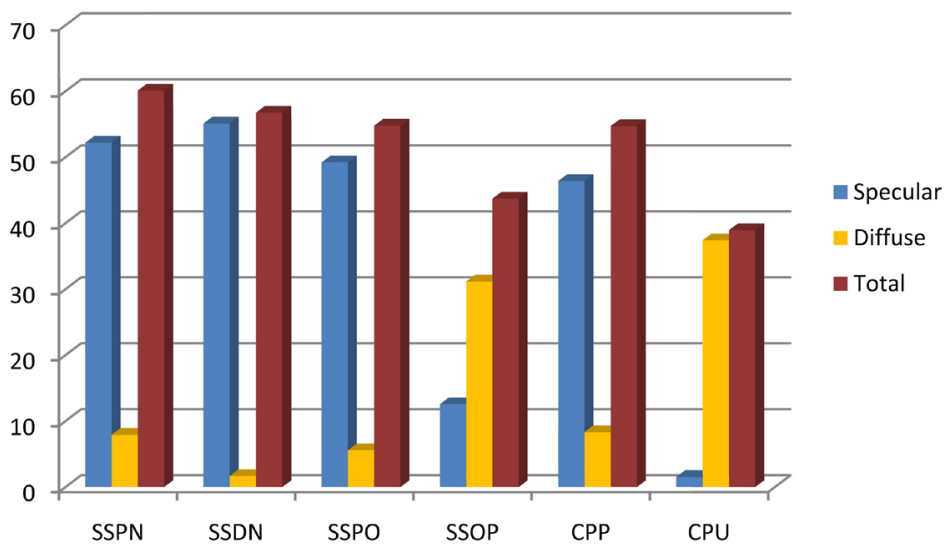

(c)

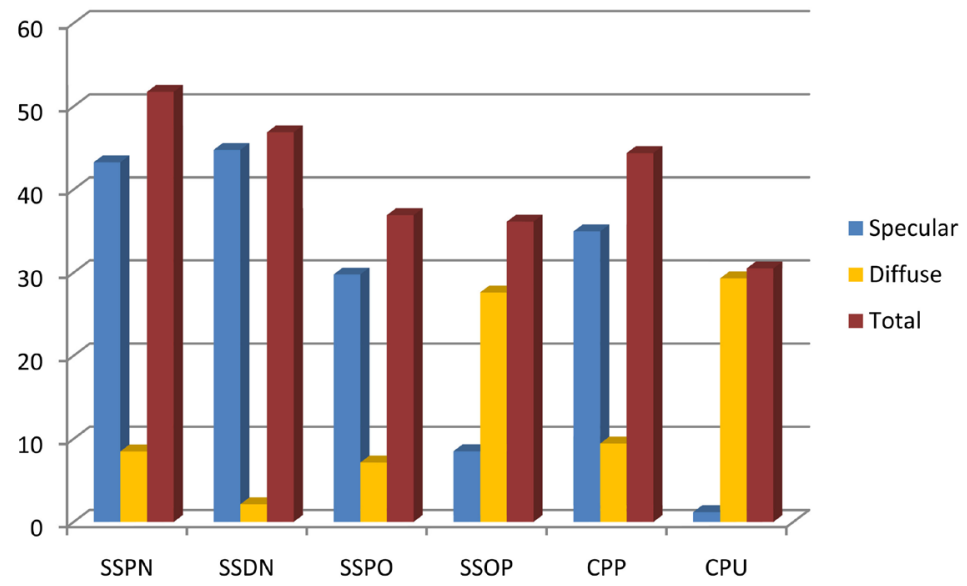

(d) 


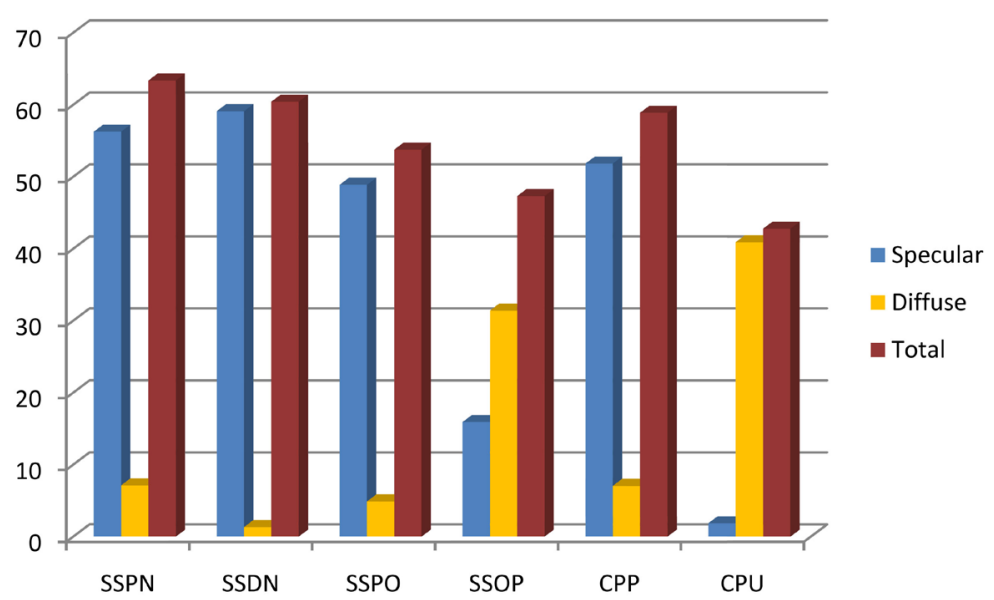

(e)

Figure 8. (a) SCI; (b) SCE, Eflectance spectra for SS-304 Samples with Different Pre-treatments; (c) Comparative values of specular, diffuse and total reflectance for SS-304 samples at $5500 \AA$; (d) Comparative values of specular, diffuse and total reflectance for SS-304 samples at $4000 \AA$; (e) Comparative values of specular, diffuse and total reflectance for SS-304 samples at $7000 \AA$.

For further discussions, reference shall be made only to reflectance values summarized in Table 11(b) for $\lambda=5500 \AA$, since it is the mean value of wavelength of visible spectra. As obvious from the table, the specular reflectance values for SSPN and SSDN lie in the narrow band of 52 - 55 units. The specular reflectance for the SS panel with the deposited oil-film, SSPO, is not far behind, with the value of $\sim 49$ units; the drastic fall in specular reflectance, however, is evident in case of the old plate, SSOP, which shows a specular reflectance value of only $\sim 12$ units, and a consequent rise in the diffuse reflectance value $(\sim 31$ units).

It is a well-established fact that light reflected from a rough surface has a larger diffuse component, compared to a smooth surface, which reflects primarily specularly. The high value of the diffused component of reflectance for old plate indicates very clearly that the surface is rougher compared with the new panels and dishes. This has already been observed in the SEM study and roughness measurements in the previous section. It may, therefore, be concluded that $8^{\circ}$ reflectance measurement is very sensitive to the texture of the metal surface.

For the panel with adsorbed oil film, SSPO, the reduction in the specular component is not very significant at $\lambda=5500 \AA$, but the reflectance data at $\lambda=$ $4000 \AA$ and $7000 \AA$ show substantial reduction in specular component compared with the clean new panels. This is also evident in the reflectance spectra shown in Figure 8(a), where the spectrum becomes quite curved at lower and higher wavelengths. The reason for this observation is not very clear.

b) Gloss measurements:

Reflectance spectrophotometer in the visible region was useful for measurements at $8^{\circ}$ angle of incidence. However, the intensity of light reflected from an object varies significantly with the angle of incidence. A glossmeter, Sheen Tri- 
microgloss 160 , has therefore been used, which can measure specular gloss at three different angles of incidence $-20^{\circ}, 60^{\circ}$ and $85^{\circ}$. However, consistent and reproducible data was obtained only at $85^{\circ}$, hence the gloss data only at this angle has been reported in the present work.

The instrument used for this purpose was Sheen Trimicrogloss 160, which uses a black polished glass $($ R.I. $=1.567)$ for calibration. The absolute reflectance values were calculated by multiplying the measured gloss by a factor of 0.6274 , which was calculated from Fresnel's theory [22] [23], with $n=1.567$. The theoretical reflectance curve of Polished black glass is shown in Figure 9 for parallel and perpendicular polarizations of incident light waves as a function of angle of incidence. It may be noted from the curve that the average reflectance value at $85^{\circ}$ angle of incidence is 62.11 for unpolarised light, which is the mean reflectance value of two polarized components. The instrument calibrates the reflectance value of black polished glass at $85^{\circ}$ as 99 units. This conversion has been done in order to enable the comparison of gloss data with the theoretical reflectance values of SS-304 panels described in the following section.

The measured gloss values at $85^{\circ}$ angle of incidence are shown along with the calculated absolute reflectance values in Table 12. The data is also plotted in Figure 10 for convenience of comparison.

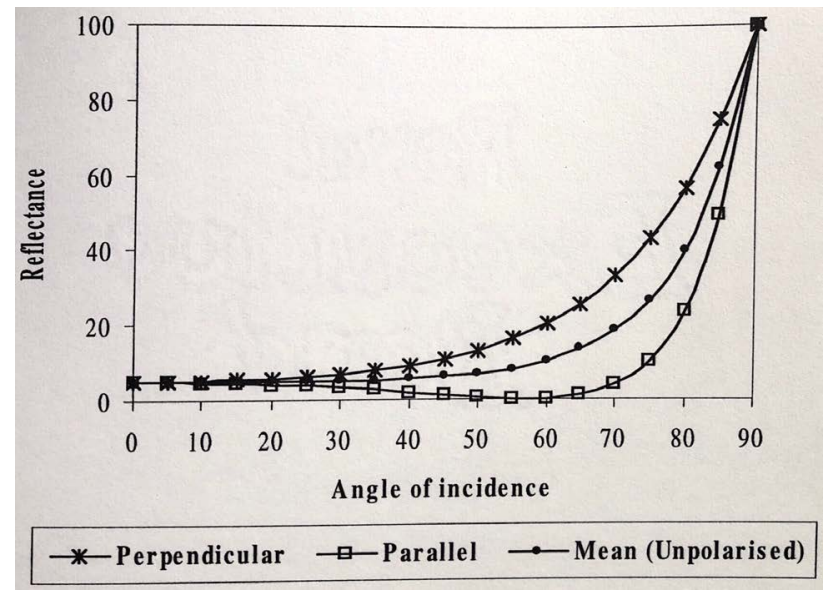

Figure 9. Theoretical reflectance curve for polished black glass.

Table 12. Gloss values and calculated absolute reflectance values at $85^{\circ}$ for SS-304 samples.

\begin{tabular}{ccc}
\hline \multirow{2}{*}{ Sample } & Measured Gloss & Absolute Reflectance \\
\cline { 2 - 3 } & $\mathrm{G}_{\mathrm{M}}$ & $\mathrm{R}_{\mathrm{A}}=\mathrm{G}_{\mathrm{M}} \times \mathbf{0 . 6 2 7 4}$ \\
\hline SSPN & 120.35 & 75.51 \\
SSDN & 125.55 & 78.77 \\
SSPO & 102.64 & 64.40 \\
SSOP & 109.56 & 68.74 \\
CPP & 91.48 & 57.39 \\
CPU & 62.48 & 39.20 \\
\hline
\end{tabular}




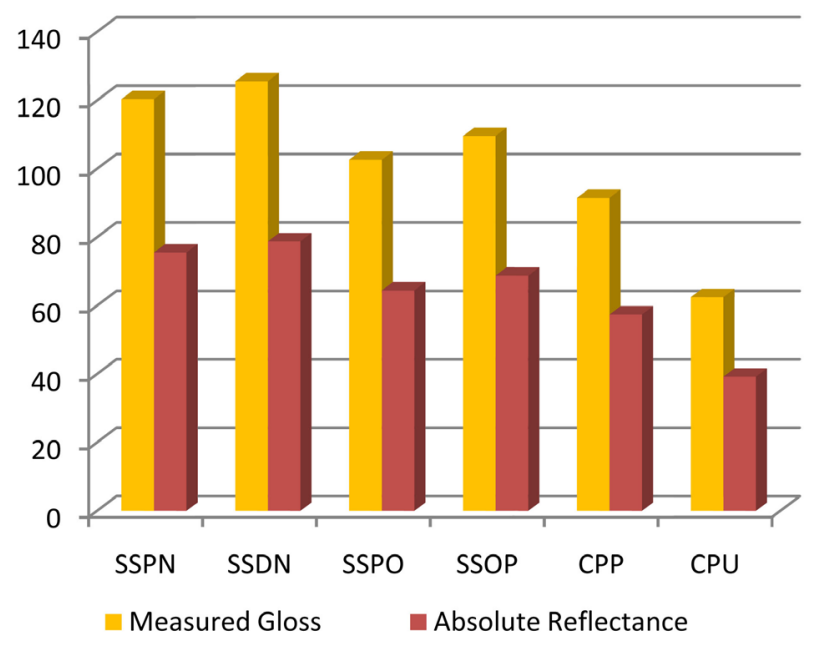

Figure 10. Comparative gloss and absolute reflectance values $\left(85^{\circ}\right)$ for SS-304 samples.

A comparison of the $85^{\circ}$ gloss data with the $8^{\circ}$ reflectance data described in the previous section shows that although the general trend is essentially similar, $85^{\circ}$ gloss values are more sensitive to the state of cleanliness of the surface. This is clearly evident from the gloss value of the clean new panel $(\mathrm{SSPN}=120.35)$ and the surface with the adsorbed oil-film $($ SSPO $=102.64)$. However, on comparison of the gloss values of the old plate (SSOP $=109.56)$ and new panel (SSPN $=120.35)$ we find that the sensitivity is much less compared with $8^{\circ}$ reflectance data. This also suggests that at $85^{\circ}$ angle of incidence, i.e. the grazing angle, even a moderately rough surface looks quite shiny.

\section{Conclusions from Physicochemical Characterization}

The results obtained from the techniques used so far, reveal two important parameters responsible for the loss of shine of brand new stainless steel plates, viz.

1) An increase in the surface roughness due to continuous usage;

2) The deposition of a thin film on the surface resulting in a dull appearance.

Any one or both of these mechanisms contributes to the loss of initial shine. It is evident from the $8^{\circ}$ reflectance measurements that surface roughness in an old plate contributes more towards the reduction in specular reflectance, compared to the presence of an oil-film. The high diffuse component is responsible for the non-shiny appearance of the old plates. The SEM as well as AFM micrographs give a clear idea of the degree of roughness in old plates compared with the new ones. Supportive evidence can also be obtained from the roughness data given by the profilometer, which clearly shows that there is a six-fold rise in surface roughness from the new panels $(0.025 \mu \mathrm{m})$ to the old plates $(0.153 \mu \mathrm{m})$. Thus, it can be concluded that surface roughness is primarily responsible for the degradation of shine of brand new stainless steel surface.

\section{Theoretical}

The results and discussions of the previous section clearly show that any form of 
surface treatment like chemical cleaning, polishing, deposition of a thin oil-film etc. considerably modifies the structure of the surface and its appearance. It is well known from literature [22] [23] that the interaction of light waves with an object can be described by four modes of light distribution:

1) Diffuse reflection;

2) Specular reflection;

3) Diffuse transmission;

4) Regular transmission.

In case of metals, the dominant mode of light distribution is specular reflection, which determines the glossiness and chromaticness (hue, saturation) of the surface whereas the diffuse reflection determines the reflection haze. Reflection from most real surfaces is neither completely specular nor completely diffuse; hence both the components must be measured accurately in order to understand the interaction of light waves with specimen surface.

The results clearly establish that surface roughness is the key parameter responsible for reduction of the original shine of the SS-304 panels and dishes. As the surface roughness increases, the intensity of the specular component of the reflected light decreases significantly with a corresponding increase in the intensity of the diffused components.

The reflection and transmission characteristics of an optically smooth surface can be described quantitatively by Fresnel's equations [24] and have been used in the current work to compute the reflectance values of the smooth metal surface. Fresnel's theory has been further extended in this work to compute the reflectance values for stainless steel alloy surface based on the reflectance values of the component metals and their composition by weight.

In order to study theoretically the light scattering behavior of SS-304 alloy panels, the following assumptions have been made as a first approximation,

1) The surface of the alloy is optically smooth;

2) Standard bulk chemical composition of SS-304 alloy is assumed to be valid in the surface region as well;

3) The four components of SS-304, viz. $\mathrm{Fe}, \mathrm{Cr}, \mathrm{Ni}, \mathrm{Mn}$ are randomly distributed in the surface region.

Under these assumptions, the mean reflectance values of optically smooth ( $\sigma$ $=0$ ) SS-304 surface may be calculated from the following equation as a first approximation,

$$
\text { Reflec }_{\mathrm{SS}-304}=0.70 R_{\mathrm{Fe}}+0.18 R_{\mathrm{Cr}}+0.10 R_{\mathrm{Ni}}+0.02 R_{\mathrm{Mn}}
$$

where $R_{\mathrm{F}}, R_{\mathrm{Cr}}, R_{\mathrm{Ni}}, R_{\mathrm{Mn}}$ are the reflectance values of the components of SS-304 alloy and the coefficients are the weighted average of their bulk concentrations.

In order to compute the reflectance of alloy surface from the above equation, the reflectance values of each component of the alloy, viz. Fe, $\mathrm{Cr}, \mathrm{Ni}$ and $\mathrm{Mn}$, have been calculated first from their respective optical constants using Fresnel's theory for a given wavelength $(\lambda)$ as a function of angle of incidence $\left(\theta_{i}\right)$.

The equations used for the computation of theoretical reflectance values for 
optically smooth metal surface are as given below:

$$
\left.\begin{array}{l}
R_{\|}=\frac{\left(n_{2}^{2}+k_{2}^{2}\right) \cos ^{2} \theta_{i}-2 n_{2} \cos \theta_{i}+1}{\left(n_{2}^{2}+k_{2}^{2}\right) \cos ^{2} \theta_{i}+2 n_{2} \cos \theta_{i}+1} \\
R_{\perp}=\frac{\left(n_{2}^{2}+k_{2}^{2}\right) \cos ^{2} \theta_{i}-2 n_{2} \cos \theta_{i}+\cos ^{2} \theta_{i}}{\left(n_{2}^{2}+k_{2}^{2}\right) \cos ^{2} \theta_{i}+2 n_{2} \cos \theta_{i}+\cos ^{2} \theta_{i}}
\end{array}\right\}
$$

where $n_{2}$ and $k_{2}$ are the optical constants of the metal and $\theta_{i}$ is the angle of incidence. For unpolarised incident light, reflectance is calculated as the mean value of $R_{\|}$and $R_{\perp}$.

$$
R_{\text {unpol }}=\frac{1}{2}\left(R_{\|}+R_{\perp}\right)
$$

The mean reflectance values of all four components as a function of angle of incidence are tabulated in Table 13 and the data are plotted in Figure 11.

The theoretical reflectance values of SS-304 alloy have been calculated using the model defined by Equation (1). The data are all summarized in Table 14.

Table 13. Mean reflectance values of four metallic components of SS-304 samples.

\begin{tabular}{ccccc}
\hline Angle of incidence & $\mathrm{Fe}$ & $\mathrm{Cr}$ & $\mathrm{Ni}$ & $\mathrm{Mn}$ \\
\hline 0 & 60.183 & 65.547 & 61.962 & 63.871 \\
8 & 60.190 & 65.556 & 61.982 & 63.884 \\
10 & 60.200 & 65.560 & 61.992 & 63.890 \\
20 & 60.227 & 65.575 & 62.063 & 63.927 \\
45 & 59.733 & 64.992 & 61.989 & 63.544 \\
60 & 58.027 & 63.085 & 61.286 & 62.127 \\
85 & 65.155 & 67.162 & 76.047 & 71.612 \\
90 & 100 & 100 & 100 & 100 \\
\hline
\end{tabular}

Table 14. Comparative results of theoretical and experimental reflectance values for SS-304 samples.

\begin{tabular}{cccccccc}
\hline \multirow{2}{*}{$\begin{array}{c}\text { Angle of } \\
\text { Incidence }\end{array}$} & $\mathrm{Fe}$ & $\mathrm{Cr}$ & $\mathrm{Ni}$ & $\mathrm{Mn}$ & \multicolumn{2}{c}{ Theoretical } & \multicolumn{2}{c}{ Experimental values } \\
\cline { 7 - 8 } & & & & & SS-304 & SSPN & SSDN \\
\hline 0 & 60.183 & 65.547 & 61.962 & 63.871 & 61.400 & - & - \\
8 & 60.190 & 65.556 & 61.982 & 63.884 & 61.409 & 60.077 & 57.555 \\
10 & 60.200 & 65.560 & 61.992 & 63.890 & 61.418 & - & - \\
20 & 60.227 & 65.575 & 62.063 & 63.927 & 61.447 & - & - \\
45 & 59.733 & 64.992 & 61.989 & 63.544 & 60.981 & - & - \\
60 & 58.027 & 63.085 & 61.286 & 62.127 & 59.345 & - & - \\
85 & 65.155 & 67.192 & 76.047 & 71.612 & 66.735 & 74.75 & 75.76 \\
90 & 100 & 100 & 100 & 100 & 100 & - & - \\
\hline
\end{tabular}




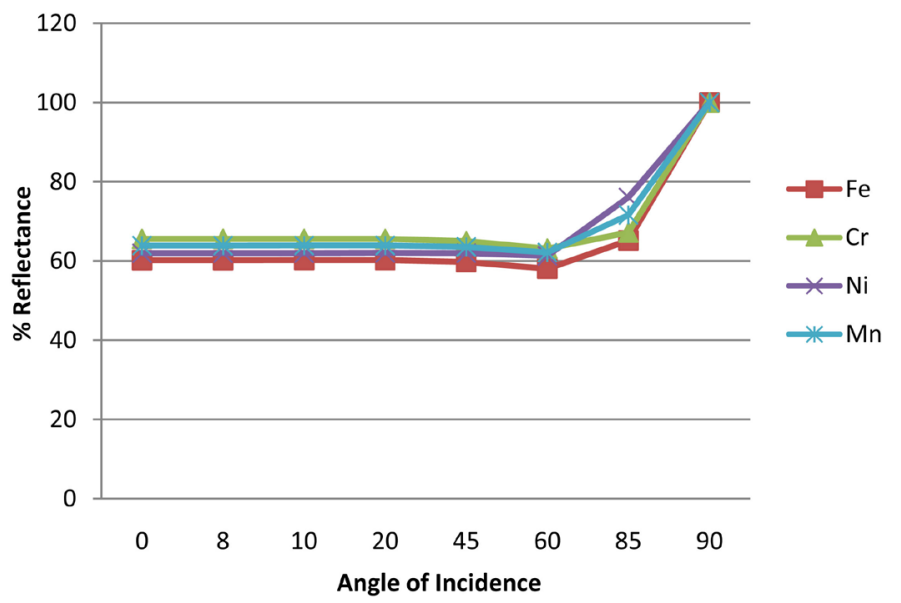

Figure 11. Mean reflectance curves for components of ss-304 alloy.

The measured experimental values of reflectance for the samples, viz. SSPN, $\operatorname{SSDN}$ at $8^{\circ}$ and $85^{\circ}$ are also incorporated in the same table for comparison. The theoretical curve along with experimental points for the same is shown in Figure 12.

From Figure 12, it is quite evident that the $8^{\circ}$ reflectance values agree very well with theoretical values at $8^{\circ}$. It has been clearly established from the experimental SEM, AFM and Profilometry studies above, that all real surfaces possess some degree of roughness. Hence, the measured values (derived from gloss values measured at $85^{\circ}$ ) reveal a $10 \%-12 \%$ deviation. To a first approximation, the theoretical and experimental values compare very well.

The reflectance characteristics of a rough surface can be described quantitatively by Beckmann's models for periodic and random rough surfaces [25]. From the analysis of the old plate (SSOP), it is evident that the real surface always shows some degree of roughness which is random in nature. Hence, the random rough surface model can be used to understand the light scattering behaviour from a real metal surface.

The relative intensity of the specular component for a random rough surface has been computed from Equation (4) given below, as a function of angle of incidence $\left(\theta_{i}\right)$ and several values of optical roughness $(\sigma)$ varying in the range of $0.0 \mu \mathrm{m}$ to $0.8 \mu \mathrm{m}$ for an incident light of wavelength $\lambda=5500 \AA$. The relevant equation is given below:

$$
I_{R S}=I_{S} / I_{S O}=\exp \left\{-\left(\frac{4 \pi \sigma \cos \theta_{i}}{\lambda}\right)^{2}\right\}
$$

where $\theta_{i}$ is the angle of incidence, $I_{R S}$ is the ratio of light intensity specularly reflected from a rough surface relative to that reflected from a smooth surface $\left(I_{S O}\right)$ of same composition [25].

The results are plotted both as a function of $\theta_{i}$ for different values of $\sigma$ (Figure 13 ) and also as a function of $\sigma$ for several values of $\theta_{i}$ (Figure 14) respectively. From Figure 13, it is quite evident that for smaller value of $\sigma$ below $0.1 \mu \mathrm{m}$, the 


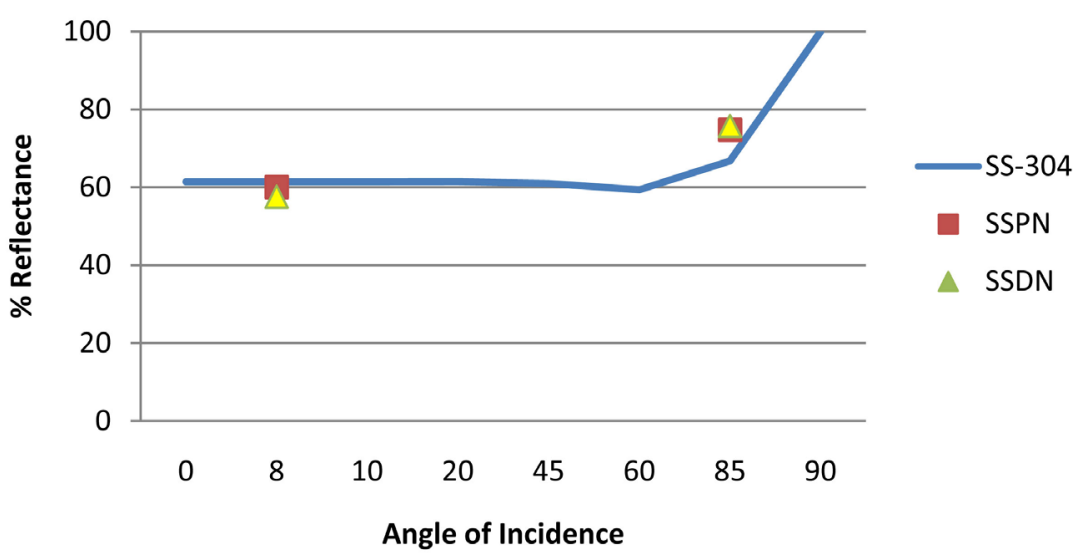

Figure 12. Theoretical mean reflectance curve as a function of angle of Incidence for SS-304 alloy [ $\mathrm{Fe}_{0.70} \mathrm{Cr}_{0.18} \mathrm{Ni}_{0.10} \mathrm{Mn}_{0.02}$ ] and experimental values for ss-304 samples - SSPN and SSDN.

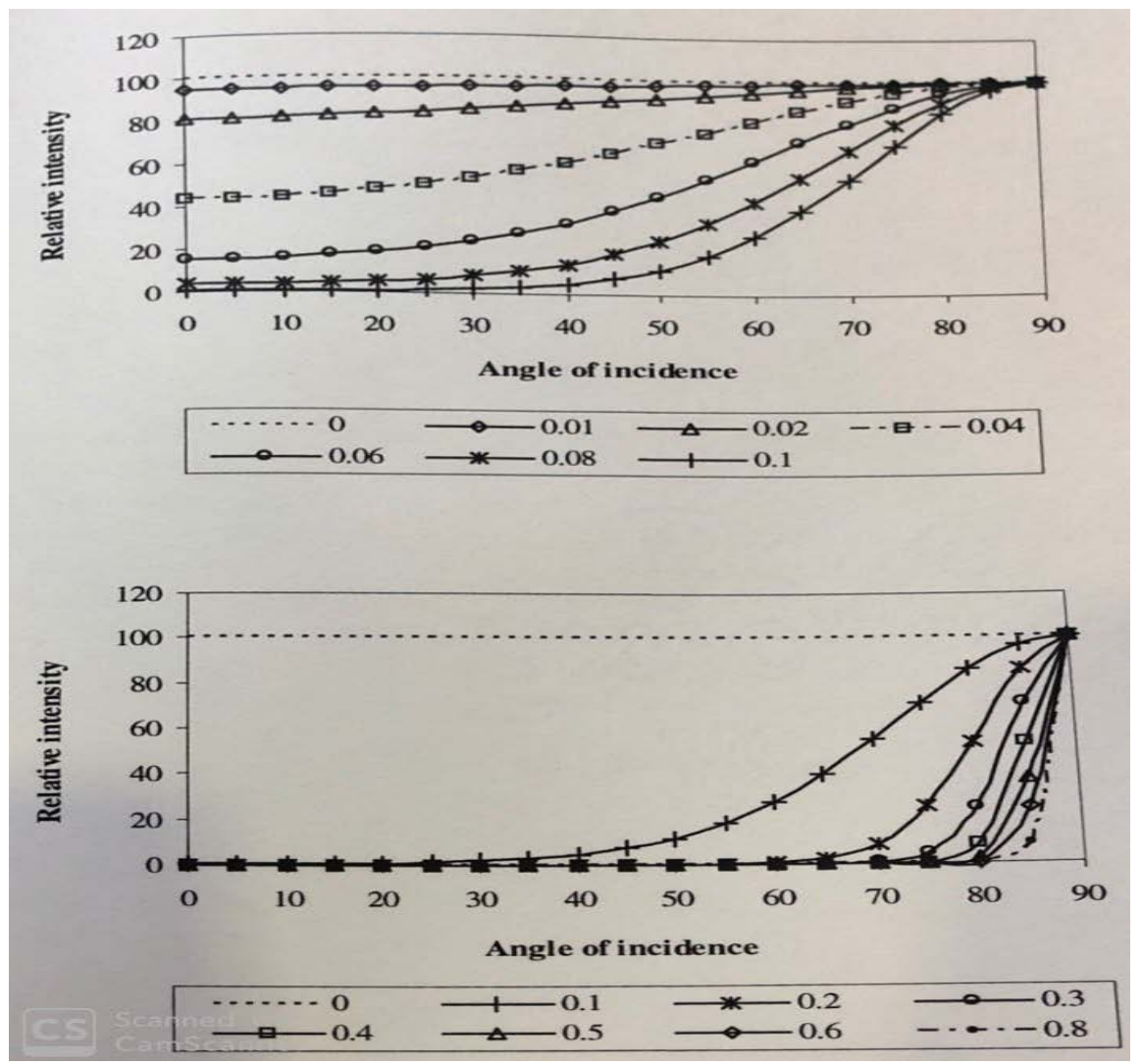

Figure 13. Variation of relative intensity of specular light reflected from a random rough surface as a function of angle of incidence for different values of optical roughness $(\sigma)$ at $\lambda=5500 \AA$.

specular reflection increases monotonically with increase in the angle of incidence. From Figure 14, it is quite evident that as $\sigma$ increases from $0.0 \mu \mathrm{m}$ to 0.1 $\mu \mathrm{m}$, the reflectance value falls rapidly from $100 \%$ to almost $0 \%$ for $\theta=0^{\circ}, 10^{\circ}$ and $20^{\circ}$, indicating that near normal reflectance measurement $\left(8^{\circ}\right)$ is not very suitable for studying the effect of roughness probably beyond the limit of $0.05 \mu \mathrm{m}$. 


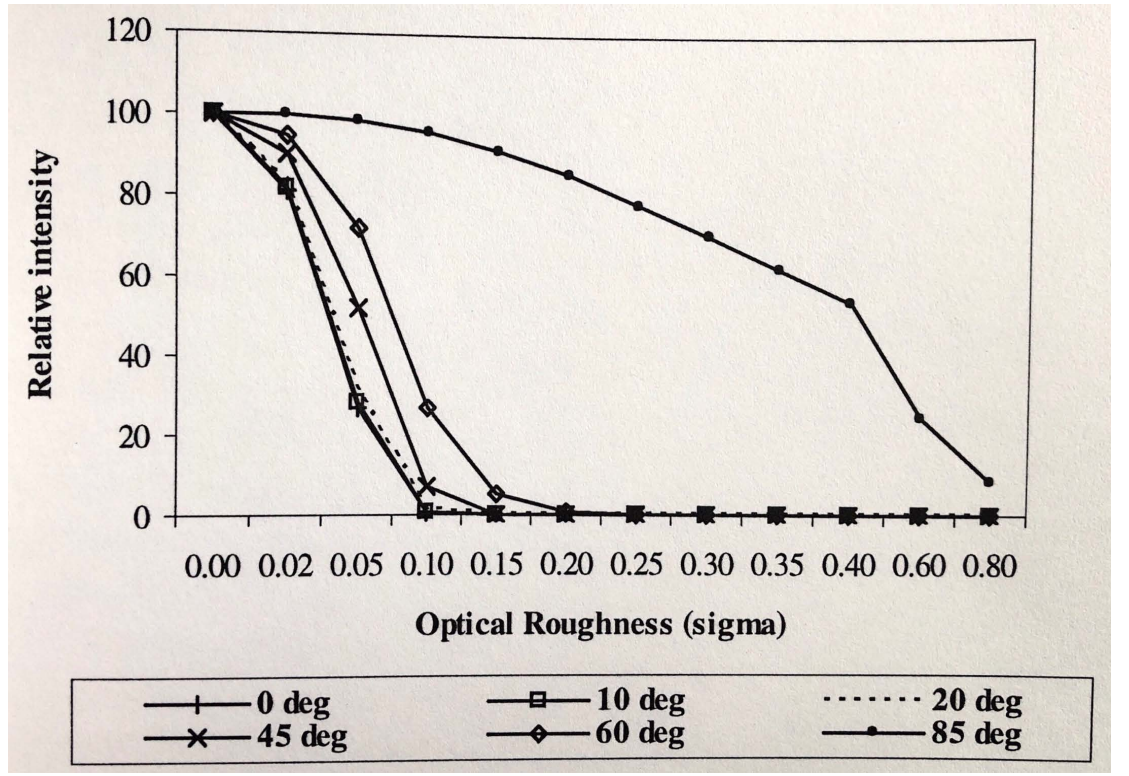

Figure 14. Variation of relative intensity of specular light reflected from a random rough surface as a function of optical roughness $(\sigma)$ for different angle of incidence at $\lambda=5500$ $\AA$.

Further, as the angle of incidence changes from $10^{\circ}$ to $60^{\circ}$, the cut-off roughness value for the specular component to become zero, changes from $0.10 \mu \mathrm{m}$ to 0.20 $\mu \mathrm{m}$. Thus, for moderately rough surface $(\sigma>0.05 \mu \mathrm{m})$, for reasonable accuracy, the measurement should be taken in the range of $70^{\circ}-90^{\circ}$.

The experimental work of Peiponen [26] confirms this view where the authors have used $\mathrm{He}$ - Ne laser $(\lambda=6328 \AA)$ to study the light scattering behaviour of several rough metal surfaces with roughness parameters varying in the range from $0.1 \mu \mathrm{m}$ to $1.6 \mu \mathrm{m}$.

The computed specular reflectance values along with the experimentally measured values for both new and used SS-304 samples have been summarized in Table 15(a) \& Table 15(b) for $8^{\circ}$ and $85^{\circ}$ angles of incidence respectively. The same have been plotted in Figure 15 as a function of surface roughness.

The measured specular reflectance value at $8^{\circ}$ for the used old sample $(\mathrm{Ra}=$ $0.15 \mu \mathrm{m})$ is 12.56 units, whereas the theoretical value vanishes at that roughness value. However, there is a reasonably good agreement between the theoretical (60.89 units) and experimental (68.73 units) values at $85^{\circ}$.

\section{Conclusions from Theoretical}

A comparison of the measured reflectance values of new SS-304 panels (SSPN and SSDN) with theoretical reflectance data computed from Equation (1) given above, shows very good agreement at $8^{\circ}$ angle of incidence and shows about $10 \%$ - $12 \%$ deviation at $85^{\circ}$ angle of incidence.

For random rough surfaces, as the optical roughness $(\sigma)$ varies from $0.0 \mu \mathrm{m}$ to $0.1 \mu \mathrm{m}$, the reflectance value falls rapidly from $100 \%$ to $0 \%$ for near normal incidence (Figure 13). For $\sigma$ below $0.1 \mu \mathrm{m}$, the specular reflectance increases 

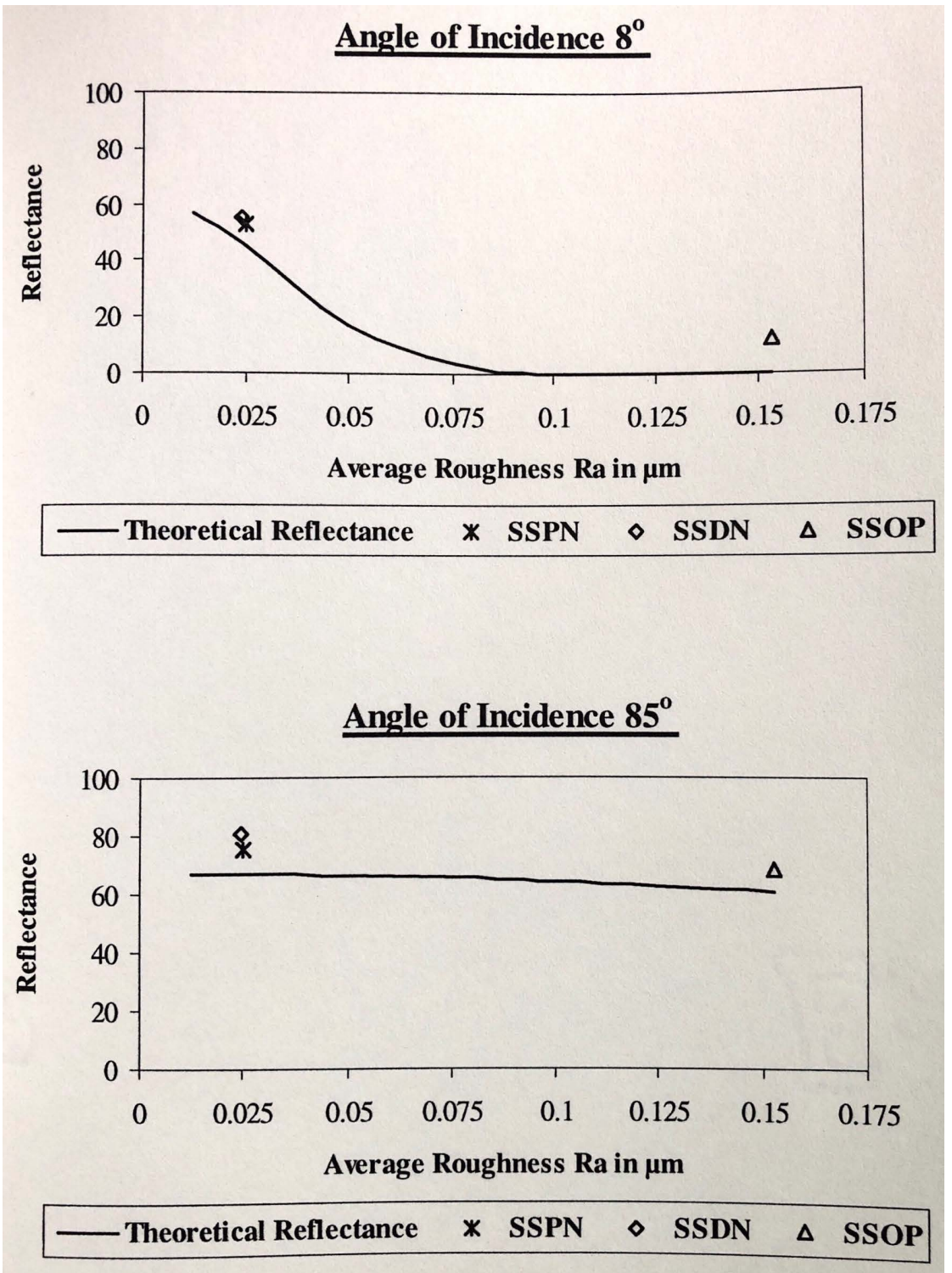

Figure 15. Theoretical reflectance curve from beckmann's model and experimental points $\left(8^{\circ}\right.$ and $\left.85^{\circ}\right)$ for New (SSPN, SSDN) and Old (SSOP) samples as a function of average roughness $\mathrm{Ra}$ at $\lambda=5500 \AA$.

monotonically as the angle of incidence increases. At $\theta_{1}=85^{\circ}$, variation of specular intensity as a function of roughness is not very sensitive.

As $\sigma$ increases from $0.1 \mu \mathrm{m}$ to $0.8 \mu \mathrm{m}$, the non-zero values of reflectance are observed only at higher angles of incidence, viz. $70^{\circ}-90^{\circ}$. For a rough surface $(\sigma>0.1 \mu \mathrm{m})$, for reasonable accuracy, the experimental reflectance measurement should be carried out in the $\theta_{1}$ range from $70^{\circ}-90^{\circ}$.

Comparison of specular component of theoretical reflectance data computed at $\lambda=5500 \AA$ from random rough surface model (Figure 15) with measured $8^{\circ}$ and $85^{\circ}$ reflectance data of old plate, SSOP $(\mathrm{Ra}=0.153 \mu \mathrm{m})$, shows considerable deviation at $8^{\circ}$ angle of incidence $(0.0006,12.56)$ and reasonably good agreement at $85^{\circ}$ angle of incidence $(60.89,68.73)$. 
Table 15. (a) Comparison of Measured ( $\left.8^{\circ}\right)$ Reflectance Values and Theoretical values for New and Old SS-304 samples $(\lambda=5500$ $\AA$ ); (b) Comparison of Measured $\left(8^{\circ}\right)$ Reflectance Values and Theoretical values for New and Old SS-304 samples $(\lambda=5500 \AA$ ).

(a)

\begin{tabular}{|c|c|c|c|c|c|c|c|}
\hline \multirow{2}{*}{ Sample } & $\begin{array}{c}\text { Average } \\
\text { Roughness }\end{array}$ & Specular & Diffuse & Total & $\begin{array}{c}\text { Optical } \\
\text { Reflectance }\end{array}$ & $\begin{array}{l}\text { Relative } \\
\text { Intensity }\end{array}$ & $\begin{array}{c}\text { Computed } \\
\text { Specular }\end{array}$ \\
\hline & $\mathrm{Ra}(\mu \mathrm{m})$ & Reflectance & Reflectance & Reflectance & Sigma $(\mu \mathrm{m})$ & $\mathrm{I}_{\mathrm{RS}}$ & $\begin{array}{l}\text { Reflectance } \\
\mathrm{I}_{\mathrm{RS}} \times 61.418\end{array}$ \\
\hline SSPN & 0.025 & 52.61 & 6.64 & 59.25 & 0.025 & 0.72857 & 44.75 \\
\hline SSDN & 0.024 & 55.16 & 2.40 & 57.56 & 0.025 & 0.72857 & 44.75 \\
\hline SSOP & 0.153 & 12.56 & 31.14 & 43.71 & 0.153 & 0.00001 & 0.0006 \\
\hline $\mathrm{X}_{1}$ & - & - & - & - & 0.100 & 0.00630 & 0.3869 \\
\hline $\mathrm{X}_{2}$ & - & - & - & - & 0.075 & 0.05784 & 3.552 \\
\hline $\mathrm{X}_{3}$ & - & - & - & - & 0.0125 & 0.92388 & 56.743 \\
\hline
\end{tabular}

(b)

\begin{tabular}{|c|c|c|c|c|c|c|}
\hline \multirow{2}{*}{ Sample } & $\begin{array}{c}\text { Average } \\
\text { Roughness }\end{array}$ & $\begin{array}{c}\text { Measured } \\
\text { Gloss }\end{array}$ & Reflectance & Optical Roughness & $\begin{array}{l}\text { Relative } \\
\text { Intensity }\end{array}$ & $\begin{array}{l}\text { Computed } \\
\text { Specular }\end{array}$ \\
\hline & $\mathrm{Ra}(\mu \mathrm{m})$ & $\mathrm{G}_{\mathrm{M}}$ & $\mathrm{R}_{\mathrm{A}}=\mathrm{G}_{\mathrm{M}} \times 0.6274$ & Sigma $(\mu \mathrm{m})$ & $\mathrm{I}_{\mathrm{RS}}$ & $\begin{array}{l}\text { Reflectance } \\
I_{R S} \times 66.735\end{array}$ \\
\hline SSPN & 0.025 & 120.35 & 75.51 & 0.025 & 0.99756 & 66.57 \\
\hline SSDN & 0.024 & 128.67 & 80.73 & 0.025 & 0.99756 & 66.57 \\
\hline SSOP & 0.153 & 109.56 & 68.73 & 0.153 & 0.91244 & 60.89 \\
\hline $\mathrm{X}_{1}$ & - & - & - & 0.100 & 0.96161 & 64.17 \\
\hline $\mathrm{X}_{2}$ & - & - & - & 0.075 & 0.97822 & 65.28 \\
\hline $\mathrm{X}_{3}$ & - & - & - & 0.0125 & 0.99939 & 66.69 \\
\hline
\end{tabular}

\section{Conclusions}

The above experimental data as well as the theoretical computations reveal two important parameters responsible for the loss of shine of brand new stainless steel plates, viz. an increase in the surface roughness due to continuous usage, and the deposition of a thin film on the surface resulting in a dull appearance.

It is evident from the experimental results that surface roughness contributes more towards the reduction in specular reflectance or the significant loss in shine as compared to the presence of an oil-film on the surface. The same conclusions can also be drawn from the theoretically computed data using Beckmann's model for random rough surface.

Thus, it can be concluded from the current work that surface roughness is primarily responsible for the degradation of shine of brand new stainless steel surface.

\section{Acknowledgements}

We would like to thank Hindustan Lever R \& D centre, Mumbai, India for providing fund for this work and Prof. J. B. Joshi, Director UDCT (ICT) for his 
support during the course of this work. We would also like to thank Prof. D. D. Kale, HOD, for providing all the facilities to carry out this work in Surface coatings and Polymer Engineering department of UDCT. The excellent support provided by the workshop staff of UDCT is gratefully acknowledged. We are also very much thankful to Dr. Sankholkar of HLL R \& D centre for a lot of interesting discussions and suggestions during the entire duration of this project.

\section{Conflicts of Interest}

The authors declare no conflicts of interest regarding the publication of this paper.

\section{References}

[1] Casper, L.A. and Powell, C.J. (1982) Industrial Applications of Surface Analysis. ACS Symposium Series, American Chemical Society, Washington DC. https://doi.org/10.1021/bk-1982-0199

[2] Somarjai, G.A. (1996) Modern Surface Science and Surface Technologies: An Introduction. Chemical Review, 96, 1223-1235. https://doi.org/10.1021/cr950234e

[3] Vickerman, J.C. (2002) Surface Analysis-The Prinicipal Techniques. Chapter 1. John Wiley and Sons, Chichester.

[4] Shrier, L.L. (1996) Corrosion. Volume 1 and 2, Newnes Buttersworths, London.

[5] Davison, R.M., Debold, T. and Johnson, M.J. (1996) Corrosion of Stainless Steel. In: ASM Handbook, 9th Edition, ASM International, OH, 547-565.

[6] American Iron and Steel Institute (1983) Finishes for Stainless Steel. 201-683-14MEB, American Iron and Steel Institute, Washington DC.

[7] Luetje, R.E. and Chalk, D.B. (1996) Surface Cleaning. In: ASM Handbook, Volume 5, Surface Engineering, ASM International, $\mathrm{OH}, 16-17$.

[8] Engstrom, S. and Backstrom, K. (1987) Ellipsometry as a Tool to Study Detergency at Hard Surfaces. Langmuir, 3, 568-574. https://doi.org/10.1021/la00076a023

[9] Truman, J.E. (1976) Stainless Steels. In: Shrier, L.L., Corrosion, Newnes, New South Wales, 3.35.

[10] Marshall, P. (1984) Austenitic Stainless Steels-Microstructure and Mechanical Properties. Chapter 1 and 2, Elsevier Applied Science, London.

[11] Davis, J.R. (1996) Surface Engineering of Stainless Steels. In: ASM Handbook: Surface Engineering, 9th Edition, ASM International, OH, 741-761.

[12] Christiaan Pistorius, P. and Du Toit, M. (2010) Low-Nickel Austenitic Stainless Steels: Metallurgical Constraints. Proceedings of the 12 th International Ferroalloys Congress: Sustainable Future, 911-917.

https://www.researchgate.net/publication/286036252

[13] Lux, G.A. and Blum, W. (1945) Methods of Polishing Steel and their effects upon the protective value of Electroplated Coatings. Part of Journal of Research of the National Bureau of Standards, 34, 295-324.

[14] Hutchings, I.M. (1992) Tribology: Friction and Wear of Engineering Materials. Edward Arnold, London, 16.

[15] Wagner, C.D., Riggs, W.M., Davis, L.E., Moulder, J.F. and Muilenberg, G.E. (1979) Handbook of X-Ray Photoelectron Spectroscopy. Perkin Elmer Corporation, Phys- 
ical Electronics Division, Gaithersburg, MN.

[16] Hercules, D.M. and Hercules, S.H. (1984) Analytical Chemistry of Surfaces. Part. II, Electron Apectroscopy. Journal of Chemical Education, 61, 483.

https://doi.org/10.1021/ed061p483

[17] Watts, J.F. (1987) The Use of X-Ray Photoelectron Spectroscopy of Organic Coatings Systems. In: Wilson, A.D., Nicholson, J.W. and Prosser, H.J., Eds., Surface Coatings, Springer, Dordrecht, 137-187.

https://doi.org/10.1007/978-94-009-3441-2 5

[18] Beamson, G. and Briggs, D. (1997) High Resolution XPS of Organic Polymers. John Wiley and Sons, Chichester.

[19] Hamed, S.M. and Allam, M.A. (2006) Application of FTIR Spectroscopy in the Determination of Antioxidant Efficiency in Sunflower Oil. Journal of Applied Sciences Research, 2, 27-33.

[20] Guillen, M.D. and Cabo, N. (2002) Fourier Transform Infrared Spectra Data versus Peroxide and Anisidine Values to Determine Oxidative Stability of Edible Oils. Food Chemistry, 77, 503-510. https://doi.org/10.1016/S0308-8146(01)00371-5

[21] Shimizu, K. (2000) GDOES Depth Profiling Analysis of the Air-Formed Oxide Film on a Sputter-Deposited Type 304 S.S. Surface and Interface Analysis, 29, 743-746. https://doi.org/10.1002/1096-9918(200011)29:11<743::AID-SIA921>3.0.CO;2-Q

[22] Hunter, R.S. and Harold, R.W. (1987) The Measurement of Appearance. 2nd Edition, Chapter 1, 3, 6, 13, John Wiley and Sons, Chichester.

[23] Thomas, T.R. (1999) Rough Surfaces. 2nd Edition, Imperial College Press, London. https://doi.org/10.1142/9781860943805

[24] Born, M. and Wolf, E. (1965) Principles of Optics. 3rd Edition, Pergamon, Oxford

[25] Beckmann, P. and Spizzichino, A. (1963) The Scattering of Electromagnetic Waves from Rough Surfaces. Pergamon Press, Oxford, London.

[26] Peiponen, K.E. and Tsuboi, T. (1990) Metal Surface Roughness and Optical Reflectance. Optics and Laser Technology, 22, 127-130.

https://doi.org/10.1016/0030-3992(90)90022-V 